\title{
Wearable Sensors for Monitoring of Cigarette Smoking in Free-Living: A Systematic Review
}

\author{
Masudul H. Imtiaz ${ }^{1}$, Raul I. Ramos-Garcia ${ }^{1}$, Shashank Wattal ${ }^{1}{ }^{\circledR}$, Stephen Tiffany ${ }^{2}$ and \\ Edward Sazonov ${ }^{1, *(1)}$ \\ 1 Department of Electrical and Computer Engineering, The University of Alabama, Tuscaloosa, AL 35487, \\ USA; masudul4145@gmail.com (M.H.I.); raul.iramosg@gmail.com (R.I.R.-G.); swattal@crimson.ua.edu (S.W.) \\ 2 Department of Psychology, University at Buffalo, The State University of New York, Buffalo, NY 12246, USA; \\ stiffany@buffalo.edu \\ * Correspondence: esazonov@eng.ua.edu; Tel.: +120-5348-1981
}

Received: 1 October 2019; Accepted: 24 October 2019; Published: 28 October 2019

\begin{abstract}
Globally, cigarette smoking is widespread among all ages, and smokers struggle to quit. The design of effective cessation interventions requires an accurate and objective assessment of smoking frequency and smoke exposure metrics. Recently, wearable devices have emerged as a means of assessing cigarette use. However, wearable technologies have inherent limitations, and their sensor responses are often influenced by wearers' behavior, motion and environmental factors. This paper presents a systematic review of current and forthcoming wearable technologies, with a focus on sensing elements, body placement, detection accuracy, underlying algorithms and applications. Full-texts of 86 scientific articles were reviewed in accordance with the Preferred Reporting Items for Systematic Review and Meta-Analyses (PRISMA) guidelines to address three research questions oriented to cigarette smoking, in order to: (1) Investigate the behavioral and physiological manifestations of cigarette smoking targeted by wearable sensors for smoking detection; (2) explore sensor modalities employed for detecting these manifestations; (3) evaluate underlying signal processing and pattern recognition methodologies and key performance metrics. The review identified five specific smoking manifestations targeted by sensors. The results suggested that no system reached $100 \%$ accuracy in the detection or evaluation of smoking-related features. Also, the testing of these sensors was mostly limited to laboratory settings. For a realistic evaluation of accuracy metrics, wearable devices require thorough testing under free-living conditions.
\end{abstract}

Keywords: cigarette smoking; ECG; IMU; respiration; RIP; signal processing; smoke exposure; wearable sensor

\section{Introduction}

Worldwide, tobacco use is a major risk factor for disease and death. Tobacco dependence, which is classified in the International Classification of Diseases (ICD-10) [1], causes several types of pulmonary and cardiovascular illness (emphysema, chronic bronchitis, heart attacks and strokes), lethal cancers (lung, colorectal, mouth, larynx, liver, cervix, etc.), and is known to affect the reproductive and immune systems [2-4]. It also increases the chance of severe health issues like diabetes, duodenal ulcers, loss of appetite, atherosclerosis, age-related macular degeneration and vision loss, premature birth and even miscarriages in pregnant women [5]. Cigarette smoking is the predominant form of tobacco use.

In 2017, an estimated 47.4 million U.S. adults (19.3\%) were reported as using tobacco products, including cigarettes (14.0\%; 34.3 million); cigars, cigarillos, or filtered little cigars (3.8\%; 9.3 million); electronic cigarettes (e-cigarettes) (2.8\%; 6.9 million); smokeless tobacco (2.1\%; 5.1 million); and pipes, water pipes, or hookahs $(1.0 \% ; 2.6$ million) [6]. Research shows that the lifespan of cigarette smokers 
is generally reduced by 13-14 years [7]. Also, the toxicants in second-hand smoke (smoke inhaled by people in the surroundings of tobacco smokers), such as carbon monoxide (CO), tobacco-specific nitrosamines (TSNA), formaldehyde $\left(\mathrm{CH}_{2} \mathrm{O}\right)$, and hydrogen cyanide $(\mathrm{HCN})$, have a deadly impact upon chronic obstructive pulmonary diseases (COPD) and asthma [8]. According to the United States Centers for Disease Control and Prevention (CDC, Atlanta, GA, USA) estimation, every year about 480,000 deaths are related to first-hand smoking (direct smoke inhalations) and 41,000 to second-hand smoke [9]. The World Health Organization (WHO) has estimated that annual deaths related to smoking will be $10 \%$ (more than 8 million people per year) by 2030 worldwide [10]. Of those deaths, $75 \%$ will be in low- and middle-income countries. There are also substantial economic consequences of smoking. In the United States alone, an annual cost of more than $\$ 300$ billion, including $\$ 170$ billion for direct medical care and $\$ 156$ billion in lost productivity, is generated by 34.3 million adult smokers [11].

Despite these statistics, "smoking cessation is often hindered by the low perceivability of health risks and the unawareness of habits in day-to-day life" [12]. Data from the National Health Interview Survey (NHIS [13]) suggest that $68 \%$ of smokers are interested in quitting, and $85 \%$ have attempted quitting at least once in their lifetime [14,15], averaging 4 quitting attempts [16], with 70\% of these quit efforts failing eventually [17]. Although there are numerous treatments available to help people quit smoking [18-24], the overall success rates of smoking cessation interventions are low. A critical starting point for these smoking cessation methods is the collection of information on the smoking habits of the individual. Self-reports of the 'number of cigarettes smoked' were among the first accepted measures of this information [25]. These approaches include self-report history methods such as 24-h/7-day retrospective smoking recall [26], immediate logging of cigarettes after consumption [27], and instrumented methods, such as ecological momentary assessment (EMA [28]). Self-report methods have improved in convenience and duration with the increased use of smartphones [29]. Clinical interventions (nicotine patches [30], personal counseling [31-34], etc.) mostly depend upon these self-report methods to understand smoking habits and estimate the degree of smoke exposure. However, these methods cannot capture detailed smoking metrics (the depth of inhalations, duration of smoke holding, the number of puffs-smoke intake per cigarette, the duration, or other aspects of smoke exposure [35]), which can support effective interventions and lapse monitoring. Also, as self-report approaches rely heavily on the user's recall and impose a burden on the smokers [25], the accuracy of these self-reports is generally limited by memory biases and intentional or unintentional misrepresentations or underreporting [36].

During the past decade, a wide range of technology-driven smoking assessments has been investigated, such as expired CO monitoring [37,38], biomarkers [39] and image processing [40-42]. However, no usable pattern of inhalations or smoking habits can be drawn from expired CO- or biomarker-based approaches [38]. A commercial handheld monitoring device, the Clinical Research Support System (CReSS) [43], was developed to acquire and store behavioral information about smoking in the natural environment. However, the use of this 'smoke-through' CReSS device may affect the pattern of inhalations in many smokers due to its obtrusiveness and large size [44]. Moreover, the ability of this device to capture all instances of smoking does demand that the people being monitored smoke all their cigarettes through the device-not all smokers are compliant with these instructions. Surveillance camera-based imaging methods require the installation of video cameras in all possible smoking locations, which is not feasible at the community level [45].

Recently, wearable sensors [46] have drawn attention as a potential solution to the problem of the passive detection of cigarette smoking and smoke exposure. Wearable sensors are lightweight, mobile, convenient, with the ability for 'collecting data anytime, anywhere and often' [47]. These devices are composed of varying sensing modalities, such as electrical, inertial (individual or multi-axis combinations of precision gyroscopes, accelerometers, magnetometers), acoustic, etc. Some approaches have used a combination of sensors. However, no single wearable method has been found to be $100 \%$ accurate for detecting smoking events in all circumstances, isolating puffs and smoke inhalations, or evaluating the metrics of smoke exposure. Some technologies suit certain environments, while others 
fail to provide good results in the same context. The sensor responses are often influenced by ambient factors, such as motion and clothing. To date, no in-depth survey or comparison (trade-off) study of these approaches has yet been performed highlighting the advantages and limitations of sensing technologies or their applicability in naturalistic settings. Also, there has been little evaluation of the underlying detection algorithms and their comparative accuracy.

This review is intended to provide a systematic evaluation of state-of-the-art wearable sensors for monitoring cigarette smoking in free-living conditions. The primary focus of this review is an up-to-date summary of recent novel approaches, individual and multi-sensor combinations, body locations, processing of sensor signals, detection algorithms and assessments of comfort. To cover the full range of the monitoring systems of cigarette smoking in this survey, research publications and commercially available sensor systems were thoroughly studied, and a total of 314 papers (without duplication) were found related to these topics. Following the application of inclusion and exclusion criteria, 108 papers were selected for a full-text review.

The paper is organized as follows. First, the methodology of the systematic review is presented in Section 2, along with the specification of the research questions (RQ). Sections 3 and 4 present the detailed exploration of these research questions, with the identification of the behavioral and physiological manifestations of cigarette smoking (Section 3), and the evaluation of wearable sensing technologies (Section 4). Section 5 discusses the challenges and potential research focus in the field of automated monitoring. Section 6 provides a summary of the review.

\section{Review Methodology}

This review of the monitoring of cigarette smoking in free-living conditions was conducted according to the Preferred Reporting Items for Systematic Review and Meta-Analyses (PRISMA) [48] guidelines. The systematic search procedure was primarily set by three authors (MHI, SW and ES), and was executed with the assistance of the remaining authors (RRG and ST). Two authors (MHI and SW) independently screened the titles and abstracts of the publications retrieved through the database search; then one author, (MHI), carried out a full-text review of all relevant studies. This methodology used the following processes:

\subsection{Identifying Research Question}

Three research questions (RQs) were chosen to guide this systematic review:

(1) RQ1. What were the behavioral and physiological manifestations of cigarette smoking targeted by wearable sensors for the detection of cigarette smoking? The answer to this question will help in understanding the rationale behind the implementation of these sensors and aid in investigating the impact of their placement on the body.

(2) RQ2. What were the sensor modalities employed to detect these manifestations? The answer to this question will identify key sensor modalities used in wearable sensors for monitoring cigarette smoking.

(3) RQ3. What were signal processing and pattern recognition methods applied to the sensor signals? Further, how was the performance of the sensors evaluated, and what accuracies were achieved? The answer to this question will help in analyzing the adequacy of current approaches and help in identifying the research gaps in current methodologies.

\subsection{Source of Studies}

Exhaustive electronic searches for relevant literature were performed across seven repositories: PubMed, Google Scholar, Science Direct, Wiley Online Library, ACM Digital library, MDPI and IEEE Explore from inception through to 30 September 2019.

\subsection{Search Strategy}

For the purpose of this review, the devices that are capable to be worn on or attached to the body, and are capable of providing usable data to the wearer, were broadly defined as wearable technology. 
To cover all wearable technologies intended for both smoking research and general use, the following 'free-text search terms' and their alternative spellings and plurals were used: 'wearable sensors', 'smoking detection', 'monitoring of smoking', 'inhalation assessment', and 'smoking cessation'. The search results were also strictly restricted to the English language. References from the selected primary full-text articles were further analyzed for relevant publications. All articles were subsequently grouped based upon common themes, such as assessed wearable devices, methods, key results, study setting and publication type. The selection was further narrowed by applying the eligibility criteria described in Table 1. Articles fulfilling the inclusion criteria were considered in this review, and those fulfilling the exclusion criteria were filtered out.

Table 1. Inclusion and Exclusion Criteria for the review.

\begin{tabular}{|c|c|}
\hline Inclusion Criteria & Exclusion Criteria \\
\hline 1. Articles published in peer-reviewed venues. & $\begin{array}{l}\text { 1. Articles that considered tobacco smoking, } \\
\text { other than using cigarettes. }\end{array}$ \\
\hline 2. Articles published since 1990. & 2. Papers not written in English. \\
\hline $\begin{array}{l}\text { 3. Articles must address a certain combination of } \\
\text { words, i.e., (cigarette smoking/ smoking detection) + } \\
\text { (sensor/ wearable) + (validation/ participant/ subject / } \\
\text { human study). }\end{array}$ & 3. Detection system other than first smoke. \\
\hline 4. Portable systems with embedded wearable sensors. & 4. Subjects under the age of 18 years. \\
\hline
\end{tabular}

\subsection{Results}

A total of 314 publications, identified through the database search, were set for the title and abstract screening; of these, 108 articles were selected for the full-text review. However, 29 failed to satisfy the eligibility criteria, and were excluded. A manual bibliographic search also identified seven additional publications qualified to be included for the full-text review. Thus, 86 publications ultimately fulfilled the eligibility criteria for this review. Figure 1 illustrates the methodology and results of the review process.

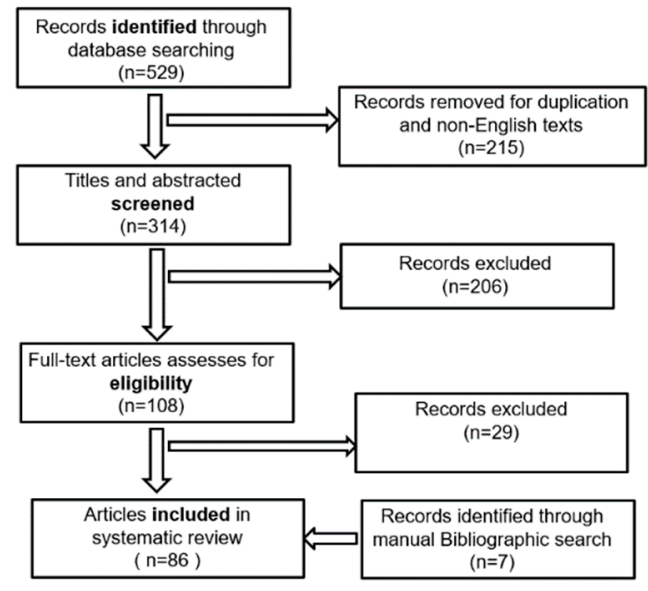

Figure 1. Flow diagram depicting the systematic review strategy.

A total of 31 publications were found (summarized in Table 2) describing the classical methods for smoking detection, including smoking self-reporting, pathological and technological methods such as CO- and biomarker-based measurement, surveillance video camera-based approaches, etc. As the key focus of this review was the detection of smoking employing wearable sensors, the detailed evaluation of these classical methods was omitted here. For the same reason, another four papers that employed smartphones to monitor the smoking habits of the user were omitted. 
Table 2. Summary of the publication related to classical methods for smoking detection.

\begin{tabular}{cc}
\hline Article Types & Total Articles \\
\hline Articles describe the self-reporting of cigarette smoking & 16 \\
Articles describe CO-measurement and biomarker-based approaches & 10 \\
Articles describe wearable and surveillance-video camera-based approaches & 5 \\
\hline
\end{tabular}

\section{Behavioral and Physiological Manifestations of Cigarette Smoking}

The philosophy behind the implementation of wearable sensors in smoking detection requires a thorough comprehension of the cigarette smoking process. The frequency or pattern of cigarette smoking generally varies between individuals or brands of the smoked cigarette; however, a few similarities between behavioral and physiological phenomena are always present $[49,50]$. An average smoker smokes a cigarette in 4-8 $\mathrm{min}$ [51] with 8-16 puffs [52]. The process starts with the removal of a cigarette from a packet, generally using fingers (sometimes using the combination of teeth and lips), putting the filtered end in the mouth, and lighting up. The number of consumed cigarettes may be tracked from the cigarette packet or holder, if it is instrumented accordingly. Also, smokers usually carry a personal lighter or match, and use it to light their cigarettes. The frequency of cigarette consumption can be identified from cigarette lighting events [12].

Once the cigarette is lit, smokers inhale and move their hands away from the mouth. This step is repeated throughout the smoking session. During puffs, the smoking hand stays vertically close to the mouth. Specifically, for inhalations, the fingers holding the cigarette reach closer to the lips and the wrist moves close to the chest. The positioning of these body parts can be used as a potential indicator of smoking events [53].

When people pull their hands closer to their mouths (from the rest) for puffing, they need to work against the pull of the acceleration due to gravity. When the hand remains stationary, close to the lips, this gravitational acceleration stays constant. When the hand returns after puffing, it works along with gravity. Smoking puffs can be identified from these hand-to-mouth gestures (HMGs). Rotations or angular motions of the smoking hand during a puff sequence also have distinguishing features. These rotations occur in a certain direction when the hand moves towards the mouth, and in the opposite direction when the hand moves away from the mouth. These rotations can also indicate smoking events [54].

Regarding smoke inhalations, smokers generally do not inhale during cigarette lighting [55], and inhale a very small amount during the initial puffs. To avoid irritation in the throat in the initial puffs, some smokers briefly hold the smoke in their mouth. Major smoke inhalations are done either by deep breathing, and occasionally by 'Frenching' (pushing some smoke back into the air without exhaling completely, and inhaling it through the nose-also referred to as a 'Chinese Drawback') [55]. A smoke inhalation can be summarized as a sequential process of: (a) A cessation of normal air-intake (breathing apnea) during cigarette holding; (b) A sharp increase of tidal volume and airflow due to smoke inhalation into the lungs; (c) Occasionally a brief period of smoke holding in the lungs, and; (d) A slow or forced exhalation, either through nose or mouth [56]. This characteristic respiration pattern may also be an indicator of smoking. Figure 2 illustrates a typical smoke inhalation in terms of changes in the lung breath volume. 


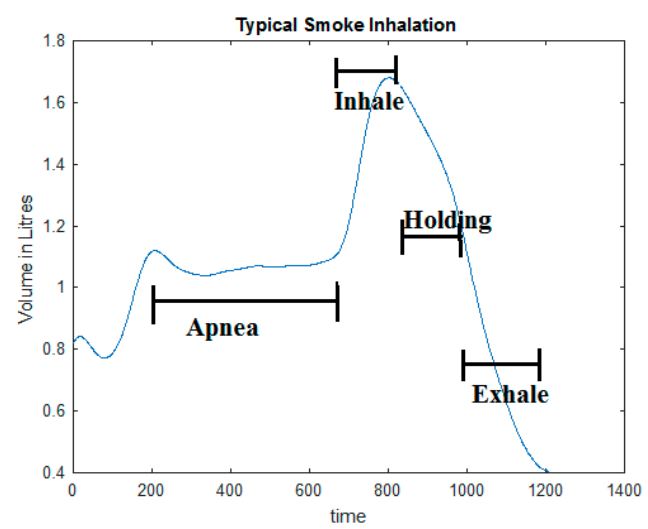

Figure 2. An illustration of a smoking-specific respiration pattern (horizontal axis: Time in milliseconds, vertical axis: Breath volume).

There is a significant difference between the acoustic properties of a smoking breath and a non-smoking breath. By characterizing these differences in a non-invasive way, it may be possible to detect the smoking episodes [57].

Some instantaneous changes in the physiological parameters of the smoker (such as blood pressure [58], and heart rate [59], etc.) also occur during smoking. These parameters, if characterized correctly, may help identify smoke inhalations.

Again, hand-oriented smoking activities (such as cigarette lighting, hand to mouth gestures and a cigarette holding between puffs) may require smokers to frequently look at their hands. An egocentric camera, such as a camera positioned on the head or chest of the person, naturally approximates the visual field of the camera wearer, and offers a valuable perspective to understand the smoking activity and their context in a naturalistic setting.

A total of 51 research studies employing wearable sensors of different modalities addressing these behavioral and physiological manifestations associated with smoking have been reported in the last decade. These approaches have been validated on a number of smoker subjects. Table 3 provides a brief summary of these publications.

Table 3. Articles on smoking detection employing wearable sensors targeting the behavioral-physiological manifestations of smoking.

\begin{tabular}{|c|c|c|c|c|c|c|c|}
\hline \multirow{2}{*}{$\begin{array}{l}\text { Phenomena Used for } \\
\text { Smoking Detection }\end{array}$} & \multicolumn{7}{|c|}{ Number of Published Papers } \\
\hline & $<2007$ & 2007-2009 & 2010-2011 & 2012-2013 & 2014-2015 & 2016-2019 & Total \\
\hline Cigarette Packet & - & - & - & - & - & - & 0 \\
\hline Lighting Event & - & - & - & 1 & 1 & 2 & 4 \\
\hline $\begin{array}{l}\text { Hand to Mouth } \\
\text { Proximity }\end{array}$ & - & - & 1 & 5 & 1 & 1 & 8 \\
\hline $\begin{array}{l}\text { Smoking Hand } \\
\text { Gestures }\end{array}$ & - & - & - & 4 & 4 & 11 & 19 \\
\hline $\begin{array}{l}\text { Smoking-specific } \\
\text { respiration pattern }\end{array}$ & 3 & - & 2 & 5 & 2 & 4 & 16 \\
\hline Breathing Sound & - & - & - & - & - & 2 & 2 \\
\hline Egocentric Vision & - & - & - & - & - & 2 & 2 \\
\hline $\begin{array}{l}\text { Total Publications } \\
\text { (By year) }\end{array}$ & 3 & - & 3 & 15 & 8 & 22 & 51 \\
\hline
\end{tabular}




\section{Evaluation of Sensing Methodologies}

\subsection{Individual Sensor Approach}

A brief evaluation of wearable sensor modalities is provided below, with the sequential responses to RQ2 and RQ3, grouping by their accomplishments in detecting smoking-related features.

\subsubsection{Detection of Smoking Frequency from Cigarette Lighting}

Sensor modalities: Unlike matches, the cigarette lighter allows for further instrumentation. Hence, a data logging system and a real-time clock may be integrated into the personal lighter to allow measurements of the frequency of cigarette consumption from ignition counts and recordings of accurate timestamps of the smoking episodes.

Embedding sensors in commercially available cigarette lighters was introduced by Scholl et al. [12] to detect lighting events prior to cigarette smoking. Three successive versions of an augmented lighter named UbiLighter [60] were introduced with an interfaced microcontroller configured to record lighter ignition events (with timestamps) in its internal memory. UbiLighter v1 (Figure 3a) was a modified electronic lighter in which closing electric contacts (by a slide down switch) triggered an interrupt to the microcontroller and heated the electric coil to ignite the lighter. UbiLighter v2 (Figure 3b) was a modified gas lighter where the microcontroller was connected to contacts that closed upon a press on the ignition button. UbiLighter v3 (Figure 3c) was based on a piezo-ignition concept where a copper contact, connected to a microcontroller, was placed in the vicinity of piezo-element to pick up a voltage when the lighter was ignited. Imtiaz et al. [61] proposed another augmented gas-lighter approach (shown in Figure 3d), employing a low-power Hall Effect sensor. The button of this lighter was instrumented by a magnet that triggered proximity events in the Hall Sensor upon button press. The details of these lighters are tabulated in Table 4. Among other commercially available electronic lighters, Quitbit [62], an internet-enabled special e-lighter, is similarly capable of measuring cigarette counts using integrated electronics in its heating coil.

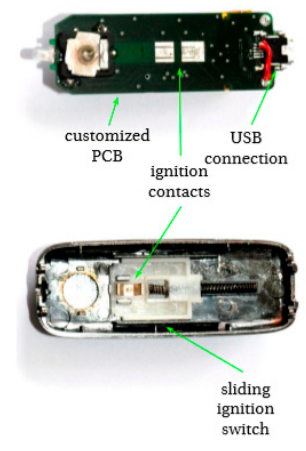

(a)

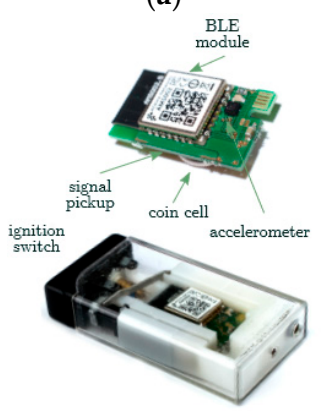

(c)

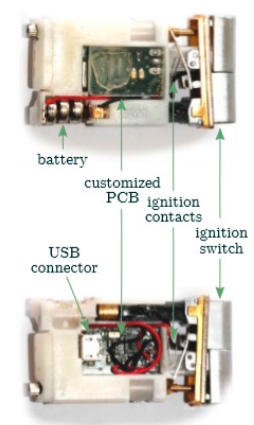

(b)

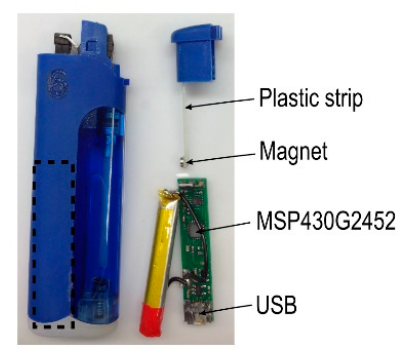

(d)

Figure 3. The instrumented lighters: (a) UbiLighter v1; (b) UbiLighter v2; (c) UbiLighter v3; (d) the Personal Automatic Cigarette Tracker (PACT) lighter (image source: $[60,61]$ ). 
Table 4. A summary of instrumented lighters employed to detect cigarette lighting events.

\begin{tabular}{|c|c|c|c|c|c|c|c|c|}
\hline Type & Versions & Type & $\begin{array}{c}\text { Lighting } \\
\text { Mechanism }\end{array}$ & Features/Limitation & Microcontroller & Interface & Battery & Validation Study \\
\hline \multirow{3}{*}{ Ubi-Lighter [60] } & V1 & Electric Coil & $\begin{array}{l}\text { Slide Down } \\
\text { Switch }\end{array}$ & $\begin{array}{l}\text { Often hard to } \\
\text { light up }\end{array}$ & Atmega32U2 & $\begin{array}{l}\text { Universal } \\
\text { Serial } \\
\text { Bus(USB) }\end{array}$ & $200 \mathrm{mAh}$ & $\begin{array}{c}3 \text { subjects } \\
\text { (11.36 } \pm 8.15 \text { days), } \\
\text { Free-living }\end{array}$ \\
\hline & $\mathrm{V} 2$ & Gas Lighter & Push Switch & $\begin{array}{c}\text { One-time } \\
\text { usage device }\end{array}$ & Atmega32U2 & USB & $30 \mathrm{mAh}$ & $\begin{array}{c}8 \text { subjects } \\
\text { (11.36 } \pm 8.15 \text { days }) \\
\text { Free-living }\end{array}$ \\
\hline & V3 & $\begin{array}{l}\text { Piezo-Ignition } \\
\text { based }\end{array}$ & Push Switch & $\begin{array}{l}\text { Contact-less data } \\
\text { transmission via } \\
\text { Bluetooth Low } \\
\text { Energy (BLE) }\end{array}$ & Atmega32U2 & USB, BLE & $48 \mathrm{mAh}$ & - \\
\hline PACT [61] & & Gas Lighter & Push Switch & Hall sensor based & MSP430G2452 & USB & $210 \mathrm{mAh}$ & $\begin{array}{l}40 \text { subjects } \\
\text { ( } 24 \text { h each), } \\
\text { Free-living }\end{array}$ \\
\hline
\end{tabular}

Signal Processing and Pattern recognition: The recorded timestamps from lighter ignition events have been used as indicators of cigarette consumption with minimal processing. In some of these approaches, closely spaced lighting events (a few seconds apart) were merged and considered as a single lighting event for two purposes: First, to debounce the ignition contact, and second, to filter incidents of the multiple ignitions sometimes needed to light a cigarette.

Evaluation: A bench test on the accuracy of lighter records was reported by Imtiaz et al. [61] with a root-mean-squared error (RMSE) value of $0.68 \mathrm{sec}$ for the timestamp of ignition events over $168 \mathrm{~h}$ (one week) vs. the true timestamp. Validation (field) study details of these instrumented lighters are also tabulated in Table 4.

\subsubsection{Detection of HMG Preceding Smoking Based on Hand to Mouth Proximity}

Sensor modality: Specific hand-to-mouth gestures of the arm during smoking have successfully been detected using Radio Frequency (RF) proximity sensors [53,61].

These electrical RF proximity sensors detected hand-to-mouth gestures preceding smoke puffs utilizing an $\infty$-shaped directional propagation pattern of rectangular loop antennas. This sensor used two battery-powered circuits. In the implementation [45], a small, low power RF transmitter $(125 \mathrm{kHz})$ was placed onto the wrist or the inner side of the lower arm of the subject's dominant hand, and a large receiving antenna was attached to the chest. A rectified proximity signal proportional to the distance between the transmitter-receiver antennas was generated employing a conditioning electronic circuit. In Scholl and van Laerhoven [54], another proximity sensor was proposed employing a miniature antenna at both transmitter and receiver ends (Figure 4). In this approach, the receiving antenna and embedded electronics were placed at the center of the thoracic area instead of a vest pocket (employed by Wu et al. [45]). A comparison of these two approaches is provided in Table 5.

Signal Processing and Pattern recognition: The sensor signal recorded from the RF proximity receiver was pre-processed by Imtiaz et al. [61] by applying an average Gaussian filter of 50 points; however, no smoothing methods were explicitly mentioned by Wu et al. [45]. The signals were marked as a valid hand-to-mouth movement if the amplitude was greater than the threshold of $100 \mathrm{mV}$ [45] and $70 \mathrm{mV}$ [61], well above their mean noise amplitudes of $90 \mathrm{mV}$ and $7.31 \mathrm{mV}$ respectively. A pattern recognition approach was reported by Lopez-Meyer (2013) [63], as an extension of the work done by Wu et al. [45], where the thresholds on amplitude, duration and time separation of hand gestures were empirically set for artifact rejection and gesture merging.

Evaluation: The amplitude and duration of HMGs preceding smoking were measured by Wu et al. [45]. The average gesture was found to be $3.78( \pm 5.42)$ sec for smoking, and $6.82( \pm 21.08)$ sec for non-smoking activities. Similarly, the average amplitude was found to be $81( \pm 21.5) \%$ and 49.3 (42.0) \% of maximum amplitude, respectively. In a study on twenty subjects performing a variety of different activities in the lab [63], the RF proximity sensor demonstrated a high recall of 0.90 in detecting hand-to-mouth gestures that precede smoking puffs. In a statistical test of artifact rejection (t-test with 95\% confidence interval), smoking while sitting and smoking while standing achieved a 
p-value of 0.000 and 0.004 , respectively. Recall before and after artifact rejection was also reported to be 0.09 and 0.30 , respectively.

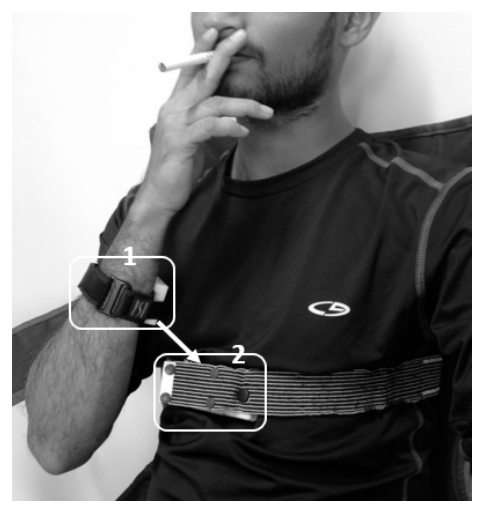

Figure 4. The concept of proximity sensor: Closeness of hand to mouth, i.e., the closeness of module 1 to module 2.

Table 5. Comparison of two versions of Radio Frequency (RF) Proximity sensors employed in smoking research.

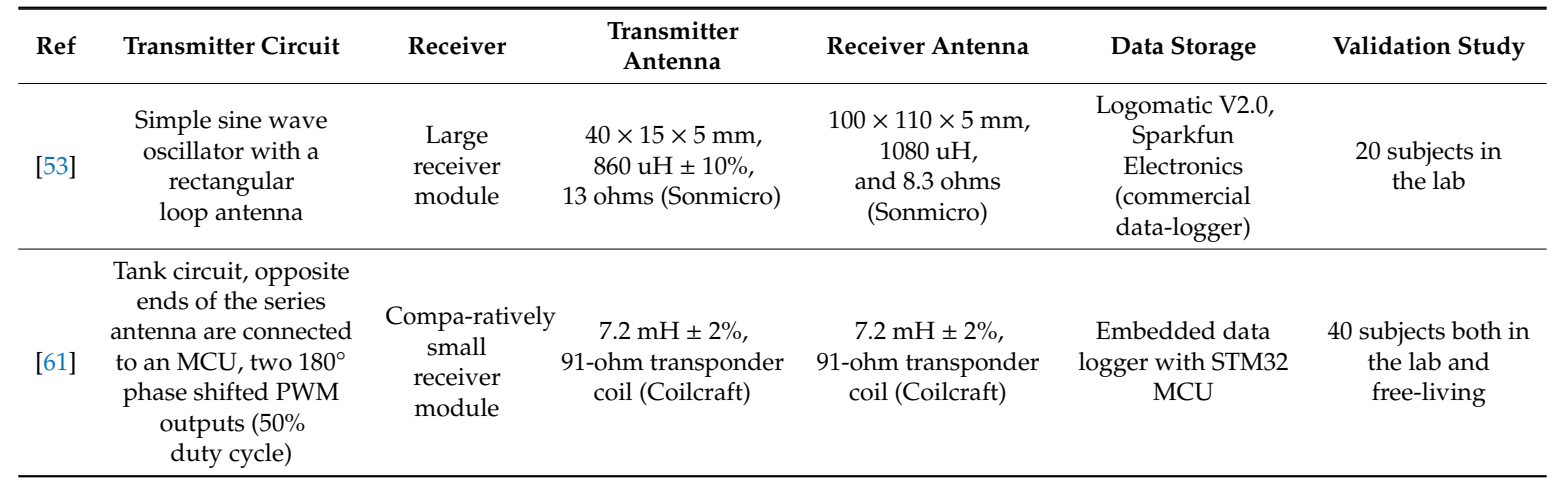

4.1.3. Detection of Smoking Events and Associated HMGs Based on Linear and Angular Movements of the Hand

Sensor modality: Inertial Measurement Units (IMUs) that measure the inclination of the smoking hand [64], i.e., the transitions of arm/wrist positions or the angular/linear velocity of the hand during smoking, have been used for the detection of the hand to mouth gestures (Figure 5). Table 6 provides a summary of inertial sensor systems (individual or combination of accelerometer, gyroscope or magnetometer) employed in smoking research.

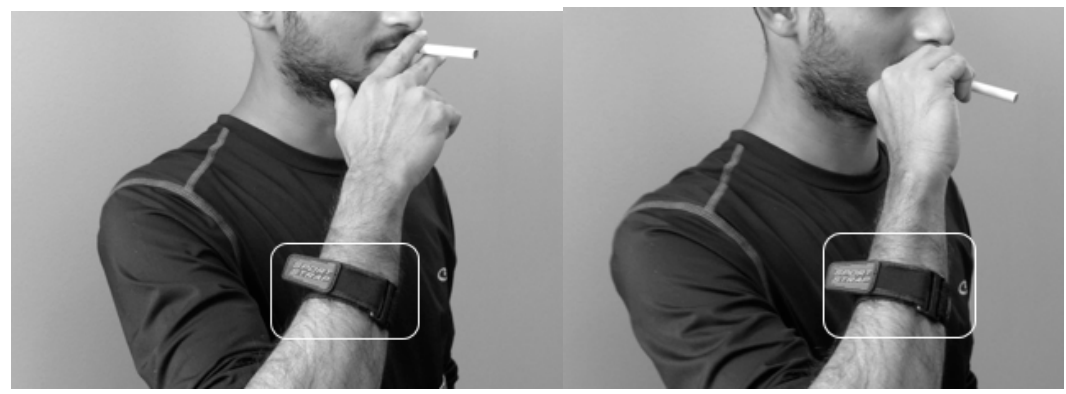

Figure 5. An instance of inertial sensor implementation on the dominant hand of smoking for detecting smoking hand gestures. 
Recently, IMUs embedded in smartwatches have been employed as substitutes for wrist worn IMUs. Cole et al. (2017) [65] and Cole et al. (Dec. 2017) [66] proposed methods to employ the accelerometers of the Apple Watch (v.2.1) with the PowerSense iOS application installed on a nearby smartphone. This same study described the alternative use of Pebble's Time Steel smartwatch with the AccelTool application. In the work by Shoaib et al. [67], the 6D IMU of a smart watch (LG Watch R). and by Añazco et al. in [68] a 6D IMU of MbientLab, were paired with smartphones and developed smoking detection applications. SmokeBeat is a similar commercial platform [69]. Further, StopWatch [70] used a standalone Android watch (LG G-Watch) to eliminate the need for a smartphone for data processing.

Table 6. Comparison of Inertial sensors employed in smoking research. IMU = Inertial Measurement Unit.

\begin{tabular}{|c|c|c|c|c|c|c|c|}
\hline Ref & IMU Type & Sensor Chip & $\begin{array}{c}\text { Employed IMU } \\
\text { Range }\end{array}$ & MCU & $\begin{array}{l}\text { Sampling } \\
\text { Frequency }\end{array}$ & Data Access & $\begin{array}{l}\text { Validation } \\
\text { Study }\end{array}$ \\
\hline [54] & $3 \mathrm{D}$ & $\begin{array}{l}\text { ADXL345 on the } \\
\text { 'Hedgehog' } \\
\text { platform }\end{array}$ & $\pm 2 \mathrm{~g}$ & PIC18F & $20 \mathrm{~Hz}$ & Embedded SD card & 4 subjects \\
\hline [69] & $6 \mathrm{D}$ & $\begin{array}{l}\text { MMA7260Q on the } \\
\text { ShimmerTM } \\
\text { Platform }\end{array}$ & $\begin{array}{c} \pm 6 \mathrm{~g} \text { and } \\
\pm 500 \mathrm{degree} / \mathrm{s}\end{array}$ & $\begin{array}{l}\text { ShimmerTM } \\
\text { Platform }\end{array}$ & $50 \mathrm{~Hz}$ & $\begin{array}{l}\text { Wirelessly } \\
\text { Transmitted }\end{array}$ & 6 subjects \\
\hline [70] & 9D & MPU-9150 & - & - & $50 \mathrm{~Hz}$ & $\begin{array}{l}\text { Wirelessly } \\
\text { Transmitted }\end{array}$ & 19 subjects \\
\hline [61] & $6 \mathrm{D}$ & LSM6DS3 & $\pm 8 \mathrm{~g}$ and $2000 \mathrm{dps}$ & STM32L151RD & $100 \mathrm{~Hz}$ & Embedded SD card & 40 subjects \\
\hline
\end{tabular}

Signal Processing and Pattern Recognition: The first step towards processing inertial sensor data was the filtering of high-frequency noises embedded in the raw signal (although the process was not explicitly mentioned in all algorithms). Table 7 provides a brief overview of the signal processing approaches (including pre-processing) of the reported smoking detection algorithms.

Employing 3D custom IMUs, Scholl and van Laerhoven [54] detected smoking events and Tang et al. [64] both puff and smoking events by applying the simple Gaussian-based and random forest classifiers used by Scholl and van Laerhoven [54] and Tang et al. [64], respectively. Bhandari et al. [71] presented a KStar classifier (from Weka Toolkit with default parameters) on 3D IMU data to detect smoking events. From the 6D IMU signal seen in the work by Raiff et al. [72], the authors applied an SVM-based learning method followed by an edge-detection algorithm to detect both smoking events and inter-puff-intervals. Lu et al. [73] developed a Random Forest-based classifier for detecting smoking events with concurrent and confound activities. Parate et al. [74] preprocessed a 9D IMU signal as a quaternion format [75] and a probabilistic model, combining the random forest and conditional random field classifier to detect both smoking events and puffs.

In this algorithm, a relative trajectory computation method was applied to the quaternion data to discriminate, recognize and classify the different types of hand gestures.

Smart watch based approaches were reported by Cole et al. (2017) [65] and Akyazi et al. [76] employing 3D IMU sensors, and Shoaib et al. [67] and Skinner et al. [70] employing 6D sensors. To identify smoking events, these approaches applied various methods, such as artificial neural network-based classification as in Cole et al. (2017) [65] and Añazco et al. [68], a combination of Cross-word Reference Template algorithm and Dynamic Time Warping with Akyazi et al. [76], a two-layer hierarchical lazy based classification by Ramakrishnan et al. in [59], and two decision tree-based classification by Skinner et al. [70]. A detailed review of current smartwatch-based smoking detection methods is presented by Parate and Ganesan [77].

Evaluation: Table 8 provides an overview of the validation studies of the wrist IMUs. Most of these validation approaches were limited to controlled laboratory settings, only Scholl and van Laerhoven [54], Parate et al. [74] and Imtiaz et al. [61] tested subjects under free-living conditions. The study reported by Skinner et al. [70] employed the highest number of participants (38) for validation, whereas only two participants were involved in the study reported by Cole et al. (2017) [65]. Unlike other studies, the studies reported by Echebarria et al. [57], Raiff et al. [72] and Parate et al. [74] applied multiple 
IMUs on different body positions and identified hand to mouth gestures related to puffs as well as smoking sessions. The highest detection accuracy was reported by Parate et al. [74], employing 9D IMUs on the wrist and elbow of the dominant hand of smoking. Here, the F1-score was 0.85 and the precision and recall were 0.95 and 0.81 , respectively. The minimum accuracy was reported by Scholl and van Laerhoven [54], with a precision of 0.51 and a recall of 0.70 in detecting smoking events.

\subsubsection{Detection of Smoking and Puffs Based on Respiratory Signals}

Sensor modality: Among different lung function measurement approaches [78-82], at present, only Respiratory Inductance Plethysmography (RIP) [83] technology has extensively been employed to identify smoking-specific breathing patterns. An example of RIP breathing sensor implementation is provided in Figure 6. Electrical Bio-impedance (BEI) Measurement-based breathing measurement has also been introduced in Imtiaz et al. [61]. The RIP sensor, which consists of a conductive thread or wire sewn, has current applied to a conductive loop, and an opposing magnetic field is generated with strength proportional to the loop's area, according to Lenz's law [84]. The RIP belt, when placed around the abdominal or thoracic area, obtains respiration signals by measuring changes in the belt's inductance caused by contraction and expansion of the lungs. This measurement is independent of the tension in the band, and not susceptible to any trapping of the RIP band to the body (unlike piezoelectric sensors [85]) or associated artifacts. Also, the bands are normally made of elastic materials, so they exert comfortable pressure and do not interfere with breathing patterns.

RIP sensors have been extensively explored to characterize the inhalation patterns associated with smoking. Initial studies [86-88] were performed only in laboratory settings (with thoracic and abdominal elastic respiratory bands) with bulky instrumentations and a computer-oriented Respitrace ${ }^{\circledR}$ RIP module [89]. Sazonov et al. [90] conducted a laboratory study employing a commercially available, portable RIP module fed to a commercial acquisition module. The module was kept in a vest pocket of the participant and captured respiration patterns from two bands. Ali et al. [91] successfully employed the single RIP band of the AutoSense sensor suite [92] over the thoracic area to mimic the breathing pattern. Similarly, in Imtiaz et al. [61], a single RIP band was implemented by sewing the device at chest level on a T-shirt to maintain higher calibration stability [93]. A summary of wearable RIP sensor systems is presented in Table 9. 
Table 7. Signal Processing and Pattern recognition techniques applied to the Inertial Measurement Unit (IMU).

\begin{tabular}{|c|c|c|c|c|c|c|c|c|c|}
\hline Ref & IMU Type & Pre-processing & Candidate Selection & Window Size & $\begin{array}{c}\text { No of } \\
\text { Extracted } \\
\text { Feature }\end{array}$ & $\begin{array}{c}\text { No of } \\
\text { Selected } \\
\text { Feature }\end{array}$ & Classifier & Detection & Validation \\
\hline [54] & $3 \mathrm{D}$ & $\begin{array}{l}\text { equalized ripple (equi- } \\
\text { ripple) FIR low-pass } \\
\text { filter }\left(\mathrm{fc}_{\mathrm{c}}=1 \mathrm{~Hz}\right)\end{array}$ & Y-axis accelerometer & $5.4 \mathrm{sec}$ & 4 & 4 & Gaussian Mixture & Smoking & $\begin{array}{c}\text { K-fold } \\
\text { validation }\end{array}$ \\
\hline [64] & $3 \mathrm{D}$ & - & RF threshold & $\begin{array}{l}25 \text { sec } 50 \% \\
\text { overlap }\end{array}$ & 5 & 5 & $\begin{array}{c}\text { Random Forest (RF), } \\
\text { Thresholding }\end{array}$ & $\begin{array}{l}\text { Hand-to-mouth gesture } \\
\text { (HMG), Smoking }\end{array}$ & 5-fold \\
\hline [69] & $6 \mathrm{D}$ & $\begin{array}{l}\text { low-pass filter } \\
(\mathrm{fc}=5 \mathrm{~Hz})\end{array}$ & Moving window & $10 \mathrm{sec}$ & 10 & 10 & $\begin{array}{l}\text { Support- vector } \\
\text { machine (SVM), } \\
\text { Edge detector }\end{array}$ & HMG, Smoking & - \\
\hline [70] & 9D & - & $\begin{array}{l}\text { Distance calculation } \\
\text { Moving window }\end{array}$ & - & 34 & 34 & $\begin{array}{c}\text { Conditional } \\
\text { Random Forest }\end{array}$ & HMG, Smoking & $\begin{array}{l}\text { 10-fold \& leave one out } \\
\text { cross validation (LOOS) }\end{array}$ \\
\hline [66] & $\begin{array}{c}\text { 6D in } \\
\text { smartwatch }\end{array}$ & - & Moving window & $30 \mathrm{sec}$ & 6 & $\begin{array}{c}4 \\
\text { (Empirically } \\
\text { chosen) }\end{array}$ & Hierarchical 2 layer & Smoking & LOOS \\
\hline [65] & $\begin{array}{l}\text { 3D in } \\
\text { smartwatch }\end{array}$ & - & Euler transformation & - & 3 & 3 & $\begin{array}{c}\text { Artificial Neural } \\
\text { Network }\end{array}$ & Smoking & $\begin{array}{c}\text { K-fold } \\
\text { validation }\end{array}$ \\
\hline [68] & $\begin{array}{l}\text { 6D in } \\
\text { smartwatch }\end{array}$ & - & Hand movement & - & 3 & 3 & $\begin{array}{c}3 \text { stage analytical } \\
\text { pipeline using Decision } \\
\text { Tree }\end{array}$ & Smoking & LOOS \\
\hline [72] & $\begin{array}{l}\text { 3D in } \\
\text { smartwatch }\end{array}$ & - & $\begin{array}{l}\text { sliding window } \\
\text { x-axis accelerometer }\end{array}$ & $10 \mathrm{~s}$ & 1 & 1 & $\begin{array}{c}\text { Dynamic Time } \\
\text { wrapping algorithm } \\
\text { (CWRT) }\end{array}$ & Smoking & LOOS \\
\hline
\end{tabular}


Table 8. Summary of detection algorithms employed on inertial sensors.

\begin{tabular}{|c|c|c|c|c|c|c|c|c|}
\hline Ref & No of IMU & $\begin{array}{c}\text { IMU } \\
\text { Placement }\end{array}$ & Dataset & Subject & Activities & Study Type & Detection & Performance \\
\hline [54] & $1(3 \mathrm{D})$ & wrist & Data of 23 days & 4 & Smoking-standing & Free- living & Smoking & Precision 0.51 , Recall 0.70 \\
\hline [64] & $4(3 \mathrm{D})$ & $\begin{array}{l}\text { Dominant wrist and } \\
\text { upper arm, } \\
\text { non-domin-ant wrist, } \\
\text { ankle }\end{array}$ & $\begin{array}{l}\text { 11.8 Hour ( } 34 \text { smoking, } \\
481 \text { puff) }\end{array}$ & 6 & $\begin{array}{l}\text { Smoking-eating, walk, Talk, } \\
\text { Drink, Stand }\end{array}$ & $\mathrm{Lab}$ & HMG, Smoking & $\begin{array}{l}\text { F1-score } 0.70 \text { for HMG, } 0.79 \\
\text { for smoking }\end{array}$ \\
\hline [69] & $4(6 \mathrm{D})$ & $\begin{array}{l}\text { Wrist, upper arm near the } \\
\text { shoulder, upper arm near } \\
\text { elbow, elbow }\end{array}$ & 21 Hour & 6 & $\begin{array}{l}\text { Smoking-sitting, walk, } \\
\text { Smoking-resting, } \\
\text { cellphone use }\end{array}$ & $\mathrm{Lab}$ & HMG, Smoking & $\begin{array}{l}\text { False Positive Rate } \\
\quad 0.07-0.2\end{array}$ \\
\hline [70] & 1 (9D) & Wrist, elbow & $\begin{array}{l}28 \text { Hour, } 369 \text { puffs ( } 48 \mathrm{~h} \\
\text { for wild) }\end{array}$ & $\begin{array}{l}\text { 15-lab, } \\
\text { 4-free-living }\end{array}$ & $\begin{array}{c}\text { Smoking-stand, } \\
\text { Smoking-talking, } \\
\text { Smoking-walking, eat, drink }\end{array}$ & Lab, Free-living & HMG, Smoking & $\begin{array}{c}\text { F1-score } 0.85 \text {, Precision } 0.95, \\
\text { Recall } 0.81\end{array}$ \\
\hline [66] & 1 (6D) in Smart watch & wrist & $\begin{array}{l}45 \text { Hour, } 17 \mathrm{~h} \text { smoking of } \\
230 \text { cigarettes }\end{array}$ & 11 & $\begin{array}{l}\text { Smoking-stand, } \\
\text { Smoking-sitting, Eat, Drink, } \\
\text { Group conversation, Sitting, }\end{array}$ & $\mathrm{Lab}$ & Smoking & $\begin{array}{c}\text { F1-score } 0.83-0.94 \\
\text { (person-independent) } \\
\text { F1-score } 0.90-0.97 \\
\text { (person-dependent) }\end{array}$ \\
\hline [65] & 1 (3D) in smartwatch & wrist & $\begin{array}{c}35 \text { smoking, } \\
155 \text { non-smoking } \\
\text { sessions, }\end{array}$ & 2 & Not mentioned & $\mathrm{Lab}$ & Smoking & Accuracy $0.85-0.95$ \\
\hline [67] & $1(6 \mathrm{D})$ in band & wrist & $\begin{array}{l}1584 \text { epochs of } \\
\text { hand gestures }\end{array}$ & 1 & Sitting, Walking, Eating & $\mathrm{Lab}$ & Smoking & $\begin{array}{l}\text { Accuracy } 0.94 \\
\text { Recall } 0.91\end{array}$ \\
\hline [68] & $1(6 \mathrm{D})$ in smartwatch & wrist & - & 38 & Smoking-sitting, Drink, Eat & Lab, Free-living & Smoking & $\begin{array}{l}\text { Precision } 0.86, \\
\text { Recall } 0.71\end{array}$ \\
\hline [72] & 1 (3D) in smartwatch & wrist & - & 26 & Smoking-stand, Eat, Drink & Lab & Smoking & F1-score 0.96 \\
\hline
\end{tabular}


Table 9. A summary of wearable Respiratory Inductance Plethysmography (RIP) sensors employed in smoking research.

\begin{tabular}{cccccc}
\hline Ref & Belt Placement & RIP Belt/ Module & Signal Output & Data storage & Validation Study \\
\hline [85] & Thoracic and abdominal & $\begin{array}{c}\text { DuraBelt Pro-Tech Inc. } \\
\text { connected to zRIP, } \\
\text { Philips Respironics, } \\
\text { Murrysville, PA }\end{array}$ & Analog Data & $\begin{array}{c}\text { Commercial data logger: } \\
\text { Logomatic V2.0, } \\
\text { Sparkfun Electronics }\end{array}$ & 20 subjects in the lab \\
\hline$[86]$ & Thoracic & AutoSense RIP belts & Analog Data & $\begin{array}{c}\text { Wireless transmission to } \\
\text { smartphone }\end{array}$ & 35 in lab and free-living \\
\hline$[61]$ & Thoracic & $\begin{array}{c}\text { SleepSense Inductive } \\
\text { Plethysmography, } \\
\text { S.L.P Inc. }\end{array}$ & Pulse Data & $\begin{array}{c}\text { Embedded data logger } \\
\text { with STM32 MCU }\end{array}$ & $\begin{array}{c}\text { 40 both in the lab and } \\
\text { free-living }\end{array}$ \\
\hline
\end{tabular}

The principle of Bioimpedance measurement is significantly different from the RIP sensor. When an alternating current pass through biological tissue, the tissue impedes the flow and causes a phase shift between the sinusoidal current and the sinusoidal voltage. Using Ohm's law, the tissue impedance can be passively calculated from the magnitude of this signal and the phase shift that is generated. Generally, high-frequency signals $(20 \sim 100 \mathrm{kHz})$ can pass through the cell membrane and enable the measurement of dynamic parameters, such as intracellular and extracellular impedances. Following this principle, equivalent changes in impedance due to the modification of tidal volume can be measured by placing electrodes close to the armpits with external high-frequency excitation. This tidal volume corresponds to the amount of air flowing into and out of the lungs, which eventually mimics the instantaneous respiration waveform. Such a bio-impedance measurement was proposed by Wang et al. [94] to capture the respiration pattern from the thorax area. The study [61] introduced a bio-impedance measurement sensor into the smoking study. Here, ADS1292R, a commercially available BioZ measurement chip, was interfaced with a microcontroller to sample and record breathing at $1 \mathrm{kHz}$.

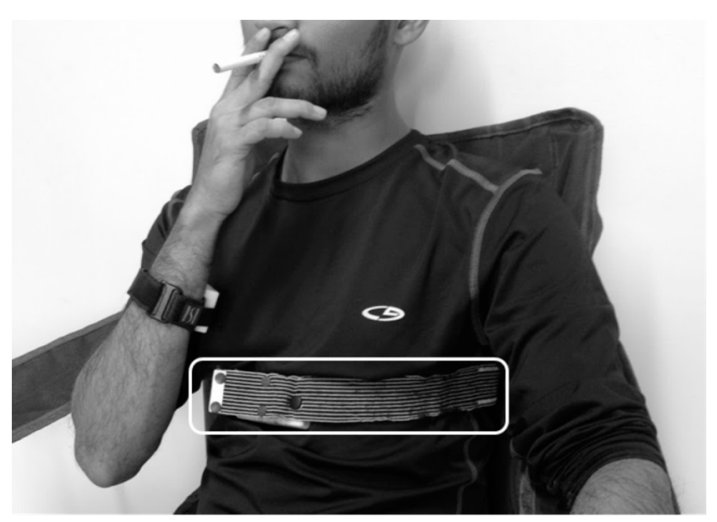

(a)

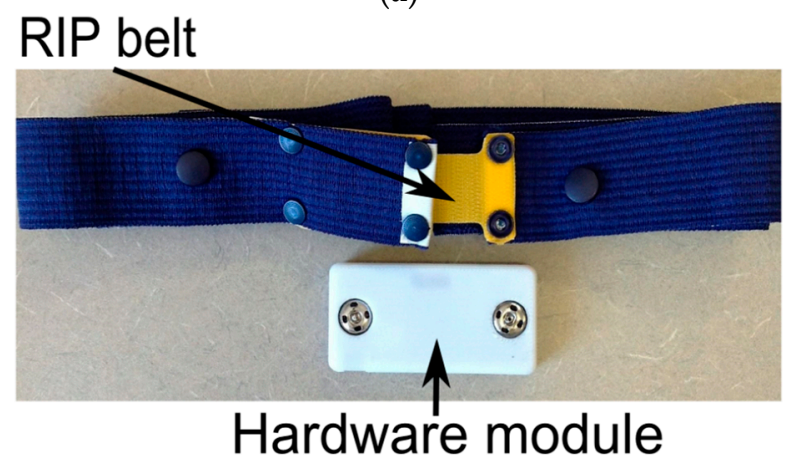

(b)

Figure 6. (a) RIP breathing sensor on chest; (b) sensor components. 
Signal Processing and Pattern Recognition: An overview of smoking detection approaches employing respiratory signals is provided in Table 10. Preprocessing of these sensor signals were necessary for the de-noising and removal of motion artifacts. The first attempt to analyze these de-noised breathing signals associated with smoking was the automatic breath segmentation [95]. In this approach, a simple breathing peak detection approach was employed for the identification of the beginning and end of a breath segment from the tidal volume (the average between the signals received from Thoracic and Abdominal breathing bands).

Recognition of daily activities that included smoking was also performed through Ramos-Garcia et al. [96] employing left-to-right hidden Markov models on tidal volume and airflow signals (the first derivate of tidal volume). A combination of a supervised and semi-supervised support vector model was proposed in Ali et al. [91] to further classify the respiration cycles obtained from a single band RIP signal into puff or non-puff events. Senyurek et al. [97] presented a Convolutional Neural Network (CNN)- and Long-Term Short Memory (LSTM)-based approach to detect smoke inhalations from RIP breathing signal and compared with a traditional machine learning (SVM)-based classifier.

In a paper under submission [98], the traditional metrics of puff duration, inhale-exhale cycle duration, smoke holding duration, inter-puff interval and novel Respiratory Smoke Exposure Metrics (RSEMs), such as inhale-exhale cycle volume and inhale-exhale volume over time were computed from the RIP breathing signal.

In the study by Imtiaz et al. [61], the generated respiration waveforms of BEI and RIP were only statistically compared with the spirometer measurements. However, BEI based method was not individually tested for the detection of smoking events.

Evaluation: Table 10 provides a summary of validation studies oriented to RIP sensors. These validations were only performed in a controlled laboratory environment with 20 subjects in Lopez-Meyer and Sazonov [95] and Ramos-Garcia, Tiffany and Sazonov [96] and 10 subjects in Ali et al. [91] mimicking daily activities. The algorithm used by Lopez-Meyer and Sazonov [95] generated an F1-score of 0.62 in identifying smoking among daily activities, whereas the algorithm used by in Ali et al. [91] found a further accuracy of 0.91 in identifying puff events. In the presence of confounding events such as stress, speaking and writing, the algorithm used by Ali et al. [91] achieved an accuracy of 0.86 in identifying smoking puffs. Also, unlike Lopez-Meyer and Sazonov in [95] and Ramos-Garcia, Tiffany and Sazonov in [96] the algorithm used by Ali et al. [91] was based on respiratory signals captured by a single band RIP sensor. In the smoking event detection by Senyurek et al. [97], the authors showed that this CNN-LSTM approach achieved an F1-score of 0.72 in leave-k-subject-out-cross-validation method whereas the classical SVM approach scored 0.63.

For puff duration, the proposed RSEM algorithm of a paper under submission [98] achieved interclass correlations (ICCs) of 0.85 and 0.87 and Pearson's correlations of 0.97 and 0.77 with video observation and CReSS, respectively. Similarly, for the inhale-exhale duration, an ICC of 0.84 and Pearson's correlation of 0.81 was obtained with video observation. The results suggest that the breathing signal may be used to compute smoke exposure metrics.

From the spirometer SVC test in Imtiaz et al. [61], the mean cross-correlation coefficient was obtained as 0.5438 between the bio-impedance and spirometer signal and 0.6275 between the RIP and spirometer. These BEI and RIP signals were also shown to be similar while the smokers performed multiple activities: standing, walking, resting idly in a chair, eating, and smoking cigarettes. 
Table 10. A summary of detection algorithms employed on RIP sensors.

\begin{tabular}{|c|c|c|c|c|c|c|c|c|c|c|}
\hline Ref & No of RIPBand & Pre-processing & De-noising & Artifact Removal & Feature Extracted & $\begin{array}{l}\text { Classifier } \\
\text { Employed }\end{array}$ & Signal Classification & Validation & Study Type & $\begin{array}{l}\text { Performance } \\
\text { Matrices }\end{array}$ \\
\hline [89] & \multirow[t]{2}{*}{$\begin{array}{c}2 \\
\text { (Thoracic TC, } \\
\text { Abdominal AB) }\end{array}$} & \multirow{2}{*}{$\begin{array}{l}\text { 1. Tidal Volume and } \\
\text { Airflow measurement } \\
\text { from TC, AB signals } \\
\text { 2. Signal } \\
\text { Normalization to the } \\
\text { range of }-1 \text { and } 1\end{array}$} & - & \multirow{2}{*}{$\begin{array}{c}\text { An ideal band pass } \\
\text { filter, } \\
\mathrm{fc}=0.0001-10 \mathrm{~Hz}\end{array}$} & - & $\begin{array}{l}\text { Simple } \\
\text { Peak-Valley } \\
\text { Detection }\end{array}$ & $\begin{array}{l}4 \text { activities } \\
\text { (resting, reading } \\
\text { aloud, food intake } \\
\text { and smoking) }\end{array}$ & $\begin{array}{l}\text { Train- } 5 \text { fold } \\
\text { cross-val; } \\
\text { Test-LOOS }\end{array}$ & $\begin{array}{l}\text { Lab, } 20 \\
\text { subject }\end{array}$ & $\begin{array}{c}\text { Accuracy: } \\
\text { Resting-0.96, } \\
\text { Reading-0.89, } \\
\text { Food } \\
\text { intake-0.91, } \\
\text { Smoking-0.89 }\end{array}$ \\
\hline [90] & & & $\begin{array}{l}\text { Average Gaussian } \\
\text { filter of } 25 \text { points }\end{array}$ & & $\begin{array}{c}\text { Z-norm } \\
16 \text { features } \\
\text { Using } \\
\text { Window } 0.5 \mathrm{~s}, 50 \% \\
\text { overlap }\end{array}$ & $\begin{array}{l}\text { Left-to-right } \\
\text { hidden } \\
\text { Markov } \\
\text { models }\end{array}$ & $\begin{array}{l}5 \text { activities (sedentary, } \\
\text { walking, eating, } \\
\text { talking, and cigarette } \\
\text { smoking) }\end{array}$ & LOOS & $\begin{array}{l}\text { Lab, } 20 \\
\text { subject }\end{array}$ & $\begin{array}{c}\text { Precision } \\
0.60, \text { Recall } \\
0.67 \\
\text { F1-score } 0.62\end{array}$ \\
\hline [86] & $\begin{array}{c}1 \\
\text { (Thoracic TC) }\end{array}$ & & - & - & $\begin{array}{l}17 \text { features from each } \\
30 \text { s window }\end{array}$ & $\begin{array}{l}\text { Supervised } \\
\text { and } \\
\text { semi-supervised } \\
\text { support } \\
\text { vector }\end{array}$ & Puff or non-puff & LOOS & $\begin{array}{l}\text { Lab, } 10 \\
\text { subject }\end{array}$ & $\begin{array}{c}\text { Accuracy } \\
0.91\end{array}$ \\
\hline
\end{tabular}




\subsubsection{Detection of Smoking Events Based on Acoustic Signals}

Sensor modality: Smoke-related breaths can be detected by non-invasive acoustic sensors applied to the throat. Figure 7 illustrates the concept of external detection of breathing sounds.

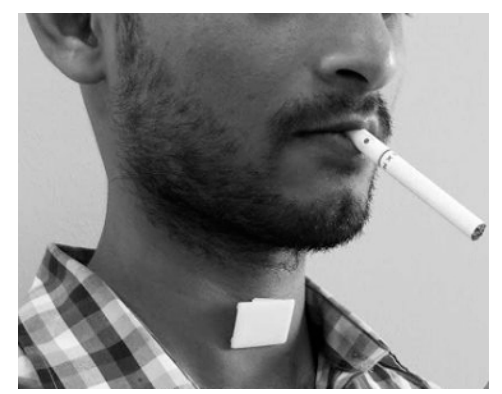

Figure 7. Acoustic sensor attached to the suprasternal notch to detect smoke related breathing.

Signal Processing and Pattern Recognition: A simple threshold-based classifier was presented by Echebarria et al. [57] for automatic identification of smoking breaths from acoustic signals. In Cui et al. [99], a hierarchical processing framework was proposed where the sub-movements of smoking from the recorded acoustic signal were detected in the lower level, and smoking puffs and sessions were detected on the higher level using a temporal sequence analysis technique. In both approaches [57,99], no de-noising method of the raw acoustic signal was explicitly mentioned.

Evaluation: The validation details of both approaches are presented in Table 11. The validation of the algorithm used by Echebarria et al. [57] involved six smoking events of 2 subjects in a lab environment, whereas the validation of [99] involved 143 smoking events of 16 subjects over a week of free-living conditions. The average recall of the algorithm used in [57] was 0.66 for the detection of smoking breaths. The algorithm applied in [99] achieved an accuracy F1-score of 0.93 and 0.92 in the detection of both the smoking puff and smoking frequency, respectively.

Table 11. A summary of acoustic sensor and validation study involved in smoking detection.

\begin{tabular}{ccccc}
\hline Ref & Sensor Details & Subject Involved & Study Details & Total Smoking Events \\
\hline$[57]$ & WADD $3,74 \times 2.4 \times 2.1 \mathrm{~cm}, 17 \mathrm{~g}$ & 2 & $\begin{array}{c}\text { In lab } \\
(1 \text { session })\end{array}$ & 6 \\
\hline$[91]$ & $\begin{array}{c}\text { Smart neckband: dual-core } 1.5 \mathrm{GHz} \\
\text { CPU, } 1 \text { GB RAM, Android } 4.2 \mathrm{OS}\end{array}$ & 16 & $\begin{array}{c}\text { Free-living } \\
(1 \text { week })\end{array}$ & 143 \\
\hline
\end{tabular}

\subsubsection{Detection of Smoking Events Based on Egocentric Camera}

Sensor modality: The smoking behavior can be monitored by a wearable egocentric camera, as the captured scenes contain details of the smoking event, smoking environment, body posture and activities during smoking. Figure 8 shows an egocentric camera-based sensor implementation.

In a paper under review [100], a laboratory test was reported for identifying the best position of camera placement on the body and maximizing the capture of images of smoking events. A low power, lightweight $(11 \mathrm{~g})$ and tiny $(6.5 \times 1.9 \times 1.5 \mathrm{~cm})$ sensor system were developed which composed of a wide-angle $\left(120^{\circ}\right)$ five-megapixel camera interfaced with an ultra-low-power microcontroller to capture and store a high resolution $(2592 \times 1944)$ image at every second up to $26 \mathrm{~h}$ on a single charge. Following the sensor placement test, the enclosure of the system was gaze-aligned with a provision on one side to facilitate the attachment to the temple of an eyeglass frame using $5 \mathrm{~mm}$ double-sided acrylic tape. The DC supply of the wearable system was routed from outside the primary enclosure and placed into another enclosure and kept in an armband while wearing the sensor system.

Signal Processing and Pattern Recognition: Captured images by the egocentric camera were manually annotated in the paper under review [100] to obtain behavioral metrics of smoking, including daily smoking frequency, smoking environment and puffs per cigarette. 
For an automatic extraction of behavioral metrics from captured images, two Faster R-CNN-based deep-learning models were developed and compared in the other paper under review [101] to (1) detect smoking events from images of lighting up a cigarette, and (2) smoking images that show a cigarette was being held in hand or mouth. Smoking information was next extracted from the detected smoking events, including the smoking time of day, frequency and inter-cigarette interval, etc.

Evaluation: The feasibility of the wearable egocentric camera was evaluated by a study performed on ten smokers to monitor full-day smoking under free-living conditions. Statistical tests (chi-square and $\mathrm{t}$-test performed in the paper under review [100]) found significant differences between the information of smoking environment and puff count captured by the camera and self-reports. The computer model presented in the paper under review [101] for automatic detection of smoking events from cigarette lighting achieved higher F1-score (0.86) and recall (0.88) than the detection from smoking images ( 0.76 and 0.80 , respectively). This study illustrated the applicability of camera-based wearable sensors for extracting an objective summary of daily smoking.

\subsection{Multi-Sensor Fusion Approach}

Generally, the fusion approach combines two or more wearable approaches in one platform to increase accuracy, synchronize utilization and simplify signal processing by eliminating the drawbacks of single-sensor approaches (presented in Table 12). Currently, three fusion sensor platforms have been introduced to enable the state-of-the-art research on smoking behavior. A summary of these platforms and the achievements of fusion approaches are presented below (with a comparison chart in Table 13):

Table 12. The comparison of key sensing modalities employed in smoking research.

\begin{tabular}{|c|c|c|c|c|}
\hline $\begin{array}{c}\text { Features of Wearable } \\
\text { Systems }\end{array}$ & $\begin{array}{l}\text { Respiratory Inductance } \\
\text { Plethysmography }\end{array}$ & $\begin{array}{l}\text { Electrical Proximity } \\
\text { Sensing }\end{array}$ & Inertial Approach & Egocentric Camera \\
\hline Body Positions & $\begin{array}{l}\text { Abdominal or Thoracic } \\
\text { area }\end{array}$ & $\begin{array}{l}\text { Transmitter on wrist and } \\
\text { Receiver on the chest } \\
\text { surface }\end{array}$ & $\begin{array}{c}\text { Mostly on wrist or lower } \\
\text { elbow }\end{array}$ & $\begin{array}{l}\text { Eye, chest or Wrist. } \\
\text { Eye-level camera was } \\
\text { explored. }\end{array}$ \\
\hline Comfort & Moderate, worn as a belt & Moderate & $\begin{array}{l}\text { High, flexible to } \\
\text { implement in body } \\
\text { locations }\end{array}$ & $\begin{array}{l}\text { High, however a privacy } \\
\text { concern exists }\end{array}$ \\
\hline Applications & $\begin{array}{l}\text { Characteristic breathing } \\
\text { pattern detection }\end{array}$ & $\begin{array}{l}\text { Characteristic hand to } \\
\text { mouth proximity }\end{array}$ & $\begin{array}{l}\text { Characteristic hand } \\
\text { gesture of smoking }\end{array}$ & $\begin{array}{c}\text { Smoking puff, } \\
\text { environment, context } \\
\text { detection }\end{array}$ \\
\hline Highest Performance & $\begin{array}{c}\text { Accuracy of } 0.81 \text { in } \\
\text { detecting puff events [86] }\end{array}$ & $\begin{array}{l}\text { Recall of } 0.90 \text { in detecting } \\
\text { hand to mouth gestures } \\
\text { preceding smoking [63] }\end{array}$ & $\begin{array}{c}\text { Precision } 0.95 \text { and F1-score } \\
0.85 \text { in detecting smoking } \\
\text { events [70] }\end{array}$ & $\begin{array}{l}\text { Recall of } 1 \text { in detecting } \\
\text { smoking events (manual } \\
\text { image review) }\end{array}$ \\
\hline Advantages & Indirect monitoring & $\begin{array}{l}\text { Good tolerance to } \\
\text { electromagnetic } \\
\text { interference }\end{array}$ & $\begin{array}{l}\text { Able to be embedded in a } \\
\text { highly wearable wristband } \\
\text { or smartwatch }\end{array}$ & Direct monitoring \\
\hline Challenges & $\begin{array}{l}\text { Accuracy needs } \\
\text { improvement }\end{array}$ & $\begin{array}{l}\text { Combination of other } \\
\text { sensors is necessary to } \\
\text { improve applicability }\end{array}$ & $\begin{array}{l}\text { Detected gestures often } \\
\text { confused with eating; } \\
\text { limited by concurrent } \\
\text { activity and confounding } \\
\text { gestures }\end{array}$ & $\begin{array}{l}\text { Privacy concern for both } \\
\text { wearer and people in } \\
\text { surroundings }\end{array}$ \\
\hline $\begin{array}{l}\text { Applicable to free-living } \\
\text { settings }\end{array}$ & Thoroughly tested & Moderately tested & Thoroughly tested & Feasibility tested \\
\hline Obtrusiveness & Unobtrusive & Unobtrusive & Unobtrusive & Unobtrusive \\
\hline Contact with Skin & $\begin{array}{l}\text { Not mandatory, can be } \\
\text { worn over clothing }\end{array}$ & Not required & $\begin{array}{c}\text { Not required if wristband } \\
\text { employed }\end{array}$ & Not required. \\
\hline
\end{tabular}




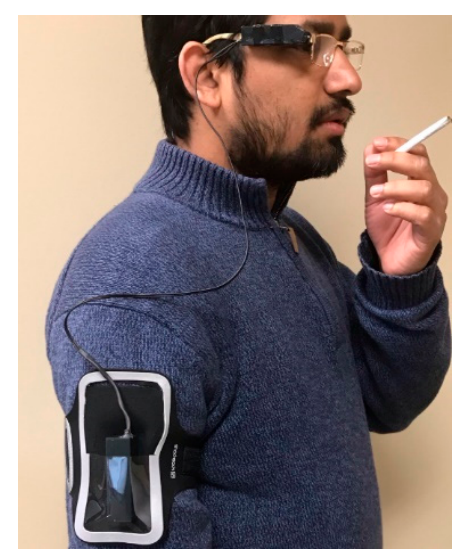

Figure 8. Egocentric camera attached to the eye-glass temple to captured details of smoking event.

\subsubsection{PACT}

Sensor modality: The first evident fusion approach was the combination of breathing and hand gesture detection sensors in a platform called Personal Automatic Cigarette Tracker (PACT [90]). PACT contained RIP module respiratory bands, an RF proximity transmitter coil, a custom-made receiver antenna and a portable data logger. PACT was able to monitor smoking by following the characteristic hand-to-mouth gestures preceding the breathing patterns specific to smoke inhalations.

Table 13. The comparison of multi-sensor approaches on a fusion platform.

\begin{tabular}{|c|c|c|c|}
\hline Fusion Platform & AutoSense & PACT & PACT v2 \\
\hline $\begin{array}{l}\text { Sensing element } \\
\text { employed in smoking research }\end{array}$ & $\begin{array}{l}\text { RIP sensing, 6-axis IMU } \\
\text { (other sensors not utilized yet in } \\
\text { smoking research) }\end{array}$ & RIP, Proximity & $\begin{array}{l}\text { RIP, Bioimpedance sensor, ECG, } \\
\text { 6-axis IMU and } \\
\text { Instrument lighter } \\
\text { (other sensors not utilized yet in } \\
\text { smoking research) }\end{array}$ \\
\hline Sampling Frequency & $\begin{array}{c}21.3 \mathrm{~Hz} \text { for RIP, } \\
16 \mathrm{~Hz} \text { for Inertial Sensor }\end{array}$ & $100 \mathrm{~Hz}$ & $\begin{array}{l}100 \mathrm{~Hz} \text { for IMU, RIP, Proximity; } \\
1 \mathrm{KHz} \text { for Physiological sensor }\end{array}$ \\
\hline Device Storage & N/A & $\begin{array}{c}\text { Portable Datalogger (Logomatic } \\
\text { V2, Sparkfun Electronics, } \\
\text { Boulder, CO) }\end{array}$ & On Board 4-GB Micro SD card \\
\hline $\begin{array}{c}\text { Sensor data } \\
\text { Transmission Method }\end{array}$ & To smartphone via ANT Radio. & N/A & N/A \\
\hline $\begin{array}{c}\text { Data } \\
\text { analysis/processing method }\end{array}$ & Published & Published & Published \\
\hline Clinical or Validation Survey & $\begin{array}{l}\text { Performed over more than } 100 \\
\text { subjects in different studies }\end{array}$ & $\begin{array}{l}\text { Performed over } 20 \text { regular } \\
\text { smokers. }\end{array}$ & $\begin{array}{l}\text { Performed over } 40 \text { regular } \\
\text { smokers. }\end{array}$ \\
\hline Tested in Free-living & $\begin{array}{l}\text { Tested over } 61 \text { regular smokers } \\
\text { in different studies }\end{array}$ & Not tested & Tested over 40 regular smokers. \\
\hline Gold Standard Comparison & $\begin{array}{l}\text { Manual annotation by } \\
\text { an observer. }\end{array}$ & $\begin{array}{l}\text { Push Button based manual } \\
\text { annotation }\end{array}$ & $\begin{array}{l}\text { Manual Video Annotation and } \\
\text { cellphone registration }\end{array}$ \\
\hline System longevity (Battery Life) & More than a day & More than a day & More than a day \\
\hline
\end{tabular}

Signal Processing and Pattern Recognition: Several algorithms were proposed in a series of publications [102-105] based on the combination of RIP breathing and Proximity sensors of the PACT system. A comparison of these detection approaches is provided in Table 14.

Similar signal pre-processing steps were followed in these algorithms, including signal normalization and de-noising of tidal volume using a Gaussian average filter and a bandpass filter. Detection methods with all these approaches started by applying thresholds to detect HMGs, forming feature vectors from both sensor signals adjacent to the beginning of HMGs, and then applying machine learning classification methods, including SVM or ensemble algorithms, such as boosting (AdaBoost), bootstrap aggregating (bagging), and Random Forests. 
Evaluation: The validity of the PACT system was tested by a study on 20 regular smokers performing 12 different activities in a controlled laboratory environment. The highest accuracy of the proposed algorithms for detecting hand to mouth gestures related to smoking was reported as 0.81 (F1-score) [103] for the subject-independent model and 0.94 (F1-score) for the subject-dependent model [103]. The minimum accuracies were reported as 0.41 [104] and 0.68 [103], respectively. In a comparative study [106], it was shown that the ensemble approaches outperformed the SVM classifier in both models. The "impact of subjects' anthropometric characteristics on the quality of sensor signals" was evaluated by Patil et al. in [104], which found that subjects with medium BMI, high BMI, and standing posture were 1.91, 4.74 and 4.32 times more likely, respectively, to have their breathing signal quality affected.

\subsubsection{AutoSense}

Sensor modality: AutoSense is an unobtrusive wearable wireless sensor suite [92] that measures several physiological and activity signals to monitor cardiovascular, respiratory and thermoregulatory systems. AutoSense combines six sensors into a wearable chest band-two ECG leads, a custom-made RIP band, a galvanic skin response (GSR) measurement system, a thermistor to measure skin temperature under the arm, an ambient temperature sensor, and a three-axis accelerometer to assess motion. AutoSense has been employed in a smoking study [107] with an additional wristband comprising a three-axis accelerometer, a 3-axis gyroscope, a 3-axis magnetometer, and two ambient-light sensors.

Signal Processing and Pattern Recognition: Data from the respiration sensor of AutoSense and wrist IMU were analyzed by Charles et al. in [88] with an algorithm tailored for recognizing smoking gestures with considerably reduced computational complexity. Preprocessing of the sensor data was done by outlier removal, i.e., discarding data when the sensors were not worn, and ignoring the segment of data packet loss in wireless transmission. From the preprocessed data, characteristic hand gestures were first identified; features were next computed from these hand gestures and corresponding respiration cycles; finally, an SVM was trained. A smoking episode was predicted in this algorithm if a cluster of smoking puffs were detected in the close temporal vicinity.

Evaluation: The validity of AutoSense sensors was tested on more than a hundred subjects both in a real-life behavioral science lab and field studies. The smoking detection algorithm proposed by Charles et al. [88] was validated on $40 \mathrm{~h}$ of data from six subjects in a laboratory environment. In a 10-fold cross-validation procedure, the proposed model achieved a recall rate of 0.96 and a false positive rate of 0.01 in detecting smoking events. This model was applied to three days of post-quit data from 32 smoking lapsers, and it correctly pinpointed the timing of the first lapse in 28 subjects. Only two false-positive episodes were detected during 20 days of abstinence. When tested on 28 subjects for the same 84 abstinent days, the occurrence of false episodes per day was limited to $\sim 16 \%$. 
Table 14. Summary of detection algorithms employed on the combination of respiration and proximity sensors.

\begin{tabular}{|c|c|c|c|c|c|c|c|}
\hline \multirow{2}{*}{ Ref } & \multirow{2}{*}{$\begin{array}{l}\text { De-noising and } \\
\text { Artifact Removal }\end{array}$} & \multirow{2}{*}{ Pre-processing } & \multirow{2}{*}{ Approach } & \multirow{2}{*}{ Key Points } & \multicolumn{2}{|c|}{ Performance Matrices } & \multirow{2}{*}{ Validation } \\
\hline & & & & & Subject-Independent & Subject-Dependent & \\
\hline [92] & \multirow{10}{*}{$\begin{array}{l}\text { 1. Gaussian } \\
\text { Average Filter of } \\
\text { 25-point sliding } \\
\text { window } \\
\text { 2. Ideal Band } \\
\text { Pass Filter: } \\
\text { fc }=0.0001-10 \mathrm{~Hz}\end{array}$} & \multirow{10}{*}{$\begin{array}{c}\text { Normalization } \\
\text { on both } \\
\text { Proximity Signal } \\
\text { and tidal Volume }\end{array}$} & SVM & - & $\begin{array}{l}\text { Precision } 0.87, \\
\text { Recall } 0.80\end{array}$ & $\begin{array}{l}\text { Precision 0.90, } \\
\text { Recall } 0.90\end{array}$ & LOOS \\
\hline \multirow{3}{*}{ [93] } & & & \multirow{3}{*}{ SVM } & 1503 Feature Vectors & F1-score: 0.81 & F1-score: 0.90 & \multirow{3}{*}{ LOOS } \\
\hline & & & & $\begin{array}{c}27 \text { Empirical } \\
\text { Feature Vectors }\end{array}$ & F1-score: 0.65 & F1-score: 0.68 & \\
\hline & & & & $\begin{array}{c}16 \text { Forward Feature } \\
\text { Selected Feature } \\
\text { Vectors }\end{array}$ & F1-score: 0.67 & F1-score: 0.94 & \\
\hline \multirow{3}{*}{ [94] } & & & \multirow{3}{*}{ SVM } & $\begin{array}{c}\text { Employing Thoracic } \\
\text { Signal (TC) }\end{array}$ & F1-score: 0.41 & F1-score: 0.85 & \multirow{3}{*}{ LOOS } \\
\hline & & & & $\begin{array}{c}\text { Employing } \\
\text { Abdominal Signal } \\
\text { (AB) }\end{array}$ & F1-score: 0.46 & F1-score: 0.88 & \\
\hline & & & & $\begin{array}{c}\text { Employing } \\
\text { Proximity Signal } \\
\text { (PS) }\end{array}$ & F1-score: 0.59 & F1-score: 0.90 & \\
\hline \multirow{3}{*}{ [93] } & & & \multirow{3}{*}{ Ensemble } & Adaboost & F1-score: 0.71 & F1-score: 0.77 & \multirow{3}{*}{ LOOS } \\
\hline & & & & Bagging & F1-score: 0.70 & F1-score: 0.82 & \\
\hline & & & & Random Forest & F1-score: 0.69 & F1-score: 0.84 & \\
\hline
\end{tabular}

\subsubsection{PACT2.0}

Sensor modality: An improved version of the PACT system called PACT2.0 was proposed by Imtiaz et al. [61], consisting of three devices: A miniature chest module to be placed at the center of the chest and attached to the RIP belt; a hand module to be worn on the wrist or forearm of the dominant hand; and an instrumented cigarette lighter. PACT2.0 contains several wearable sensors (Inertial, RIP, Electrical Proximity, physiological sensors such as Bioimpedance measurement and an ECG sensor) to monitor breathing, respiration rate, heart rate variability, hand-to-mouth gestures, posture and motion. In addition, PACT2.0 acquires and stores GPS location data, allowing the geospatial analysis of smoking events. Finally, the instrumented lighter keeps a log of all lighting events to increase the overall reliability of the system by an independent measurement of smoking behavior.

Signal Processing and Pattern Recognition: Senyurek et al. (Jan. 2019) [108] proposed an algorithm to identify the smoking session and smoking-related HMGs, integrating two PACT2.0 sensors: The instrumented lighter and the $6 \mathrm{D}$ wrist IMU. In the preprocessing steps, the raw IMU sensor signal was filtered by a 2nd order low pass Butterworth filter. Candidate HMGs were then detected from wavelet-filtered accelerometer 1D x-axis data, and an SVM classifier was trained. A two-level correction method was finally applied: A kernel-based smoothing and the identification of the start of the smoking session from the records of the instrumented lighter.

Using a similar combination of wrist IMU and instrumented lighter, Senyurek et al. (May 2019) [109] proposed to detect smoking events from the regularity of hand gestures estimated from a single axis of the accelerometer. In this approach, an unbiased autocorrelation method was applied to process the temporal sequence of hand gestures and to quantify the regularity score. A smoking episode (the start of smoking and duration) was predicted in this algorithm from lighting events and regularity scores.

In the paper under review [110], cycles of smoking inhalation were detected from RIP and IMU sensor signals employing deep learning models. $\mathrm{CNN}$ was first employed to automate feature learning from raw sensor streams. LSTM network layers were then used to capture the temporal dynamics of sensor signals and classify time segmented sequences.

Imtiaz et al. (2019) [111] proposed a smoking detection method using associated changes in metrics derived from the heart rate. To differentiate these changes from the impact of intense physical activities, the proposed system captured breathing (employing the bioimpedance sensor of PACT 2.0) and body motion (PACT 2.0 accelerometer placed on chest) along with heart rate (ECG sensor 
of PACT 2.0). A support vector machine-based classifier was developed on fifteen features of these sensor signals selected by a forward-feature selection method. A Gaussian kernel smoothing method was applied to the classifier outputs to identify the individual smoking session.

Evaluation: The smoking detection algorithms proposed in Senyurek et al. (Jan 2019) [108] were validated on 35 subjects in a controlled laboratory setting for three hours and free-living settings for $\sim 24 \mathrm{~h}$. In a leave-one-out-cross-validation on $\sim 55 \mathrm{~h}$ of laboratory data, the combined approach [108] reached accuracies of 0.97 and 0.93 , and F1-scores 0.98 and 0.86 for detecting smoking activity and individual HMGs, respectively. This model was also validated on $\sim 816 \mathrm{~h}$ of free-living data with a reported accuracy of 0.82 in detecting smoked cigarettes in naturalistic settings. A comparable accuracy of 0.83 (F1-score: 0.91) was reported by Senyurek et al. (May 2019) [109] in identifying free-living cigarette smoking from the regularity of hand gesture and lighting events. Also, in Senyurek et al. (Jan. 2019) [108], authors identified that smokers under surveillance consumed cigarettes much faster ( $\sim 5.6 \mathrm{~min})$, with a higher number of hand to mouth gestures (15.04 gestures/cigarette) than under free-living conditions ( $7.5 \mathrm{~min}, 8.9$ gestures/cigarette).

The detection model of smoking inhalation presented in the paper under review [110] was evaluated on 467 free-living smoking events collected from 45 subjects over $42.7 \mathrm{~h}$. This model achieved an F1-score of 0.78 in Leave-One-Subject-Out (LOSO) cross-validation.

In other LOSO validation, the physiological sensor-based approach [111] detected smoking events (187 out of total 232) with the recall and F1-score accuracy of 0.87 and 0.79 , respectively, in the laboratory setting (known activities) and 0.77 and 0.61 , respectively, under free-living conditions.

\section{Discussion}

This review was intended to provide a systematic evaluation of existing wearable sensors for the objective detection of behavioral and physiological manifestations associated with cigarette smoking. This review identified five specific phenomena related to cigarette smoking that were targeted in the development of wearable sensors. The review also explored 51 research publications describing methods to identify and evaluate smoking-related features assessed through individual sensor systems or their combinations.

The review found evidence that instrumented lighters can capture the initiation of a smoking sequence, and are capable of collecting data on smoking frequency in an unobtrusive way. Further, the lighter can be used in multi-sensor approaches for establishing the beginning of a smoking session. However, if the smoker uses a different lighter than this instrumented one, those particular smoking events will not be detected.

Studies covered in this review suggested that RF Proximity sensors can be effective tools for determining the frequency and duration of hand gestures preceding smoking. In a typical cigarette holding gesture, RF antennas were reported by Sazonov et al. [53] to produce the highest magnitude of signal strength relative to hand gestures associated with other activities (such as eating). However, these differences in signal amplitude may not be sufficient to differentiate among general hand-to-mouth gestures [63], but may be capable of providing supportive features to be used for the analysis of smoking patterns in multi-sensor approaches. Furthermore, this approach is typically used to detect gestures of the dominant hand; any smoking using a non-dominant hand (e.g., while driving) will also go undetected. The effectiveness of this method might be limited if a subject generates more frequent hand movements (not related to smoking) near the face. Also, the method will not be able to distinguish whether a person is smoking or resting/reading while supporting his chin with the smoking arm or hand.

IMUs were also found useful for detecting transitions of arm positions during smoking. Initial research with this approach involved the placement of multiple IMUs (3D or 6D) on different hand positions. However, recent research has focused on single IMUs. The 9D IMUs were also employed where concerns of battery longevity were not present. However, IMUs cannot provide information about the absolute position of the arm and its proximity to the mouth. The central 
challenge of the IMU-based approach is to recognize a smoking gesture 'in the wild' without any explicit information from the plethora of other gestures that a user performs each day. Furthermore, there are significant signal variations due to the changes in the users' body orientation. When people swing their hands during smoking or in conversation, smoking hand gestures are difficult to identify. In some cases, wrist-worn sensors may not remain fixed in the initial placement position, and the sensor responses may vary under free-living conditions. Also, concurrent activities (e.g., walking, talking) while smoking modifies the characteristic pattern of the smoking gesture. Smartwatches also have these inherent limitations; however, they might facilitate real-time intervention (with or without pairing with smartphones).

RIP sensors are effective in capturing variations in the volume of inhaled smoke, the duration of inhalation and breath-holding time, and in bronchial reactivity. The breathing patterns measured through RIP sensors are highly susceptible to artifacts caused by hand and body motions. Stress, speaking, walking or other confounding events also had some effects on respiration measurements [91]. Processing of RIP sensor signals and robust classification algorithms are required to detect smoking patterns. RIP devices may also be cumbersome if worn for an extended period. Unlike initial implementations, recent RIP approaches contain miniature data logging modules with more comfortable elastic bands. Nevertheless, there are ongoing concerns and issues with clothing integration, cleaning and obtrusiveness of the devices.

Bio-impedance measurement systems are free of the limitations of integration with clothing, however, they require electrode attachment to the body. A combination of Bio-impedance based breathing sensor, ECG sensor and accelerometer placed on the chest was employed by Imtiaz et al. (2019) [111] for the detection of smoking events. However, the model suffered from many false positives, especially in free-living conditions. This study assumed that changes in heart rate parameters during the study period were either due to cigarette smoking or intense physical activities. Any physiological or ambient factors (with light physical activities) that could lead to a change in heart rate parameters might have caused false positives with this approach. Also, the impact of smoking on physiological signals or the influence of concurrent activities would likely vary greatly among people. Wattal et al. [112] presented textile electrodes and connectors, which can be evaluated to ease the data collection of the ECG and bioimpedance signals.

Smoking detection based upon acoustic signals is susceptible to ambient noise, hence robust signal processing methods for speech and artifact rejection are necessary for high accuracy. The visibility of this sensor system to others might limit the mass implementation of this approach.

Despite the limitations of wearable sensors and the failure of sensor systems to be $100 \%$ accurate in the detection of smoking events in all circumstances, extant systems have identified interesting smoking-oriented phenomena. For example, research using instrumented lighters substantiated the idea that smokers tend to overestimate their smoking consumption, and may be unaware of many instances of their daily smoking [12]. The instrumented lighter has also identified daily recurrent patterns of smoking incidents on an individual basis [12]. Work with the breathing sensor has verified that smoking displays a specific breathing pattern [58]. Further, the combination of breathing and proximity sensors identified individual traits in breathing patterns [102]. This combination of sensors also demonstrated that anthropometric characteristics (such as obesity, gestures) of the person affect the quality of smoking-specific breathing signals [104]. Finally, a combination of inertial sensors and instrumented lighters revealed that smokers under surveillance consume cigarettes much faster with a higher number of hand to mouth gestures than when in free-living conditions [108].

Additional successes with wearable sensors in smoking research are likely to be achieved if factors such as size and comfort of wearable systems, applicability in daily usage and inconspicuous monitoring are addressed. Due to their form factors, custom wrist-worn inertial sensors or smart-watches might be relatively easier to adopt for daily usage. RIP breathing or acoustic sensors tend to be obtrusive and somewhat cumbersome if worn for an extended period. Hence, the miniaturization and commercialization of these sensor systems will foster their acceptance by all types of smokers. 
The camera-based system provides a direct way (from images of lit cigarettes) to detect smoking. Unlike other sensor systems, this sensor could identify the smoking environment, social interaction and locations that may promote smoking. This information related to activity and context during/immediately prior to smoking could play an important role in developing smoking intervention methods. The timestamp embedded in these images can provide additional information on the smoking time of day, duration and frequency. In the feasibility study involving 10 participants, all smoking events were correctly detected; however, it requires further validation, involving many participants of varying age and demographic profiles.

Most of the validation of the above-mentioned systems was limited to laboratory settings. These systems need systematic evaluation under extended free-living conditions. These evaluations need to gather more detailed information about intrusion and comfort. Also, these methodologies need to be tested for significantly longer periods of time (weeks/months) to fully examine their operation before they can be employed for general use.

The number of participant's involvement varied between validation studies. Out of 51 reviewed articles, 40 studies involved more than 10 smoker subjects (two studies involving instrumented lighter, eight involving RF proximity sensor, 12 involving inertial sensors, 16 involving breathing sensor, one involving acoustic sensor, one involving egocentric camera). However, the remaining 11 studies had tests conducted in very small populations (less than 10, as low as two participants). Since the focus of this review was the presentation of all proposed sensors for smoking detection and characterization, no papers were excluded due to the small study size. However, the strength of the conclusions drawn from such studies is limited.

Individual smoking patterns can be influenced by a variety of factors such as location (e.g., smoking zones, automobiles), ambient conditions, and physical postures (walking, standing, sitting, and relaxing). However, no study on wearable sensors has systematically analyzed the impact of these contextual factors on smoking. Hence, the available mobility sensors in the PACT 2.0 platform (GPS or pedometer) can be evaluated to investigate their impact on improving the accuracy of current smoking detection methods.

Data recording is another important aspect of the available systems. Custom-made sensor systems have either onboard flash storage or the capability of wireless transmission to a nearby receiver or smartphone. In most of these approaches, data can only be accessed offline for computer analysis and cannot assist smokers to react immediately to their smoking situations. The smartwatch based IMU approach [65], [113], introduced methods to implement real-time detection algorithms at the smartphone to facilitate real-time interventions. The study reported by Skinner et al. [70] provided an approach to eliminate the necessity of smartphones and integrated everything into a single node (a wristwatch). McClernon and Choudhury [114] and Qin et al. [115] proposed methods to use only smartphone sensors (Wi-Fi, GPS, and Accelerometer) data to detect smoking events. These above-mentioned approaches may be capable of recruiting social support groups to inhibit smoking behavior. For more robust interventions, a blend of a Smartwatch platform with other fusion modules could be explored. These systems could even relate to devices on an Internet of Things (IoT) network to develop new intervention strategies.

\section{Future Directions}

This review demonstrates that the monitoring of cigarette smoking by wearable systems is still in an early stage of development and requires considerable research before it is suitable for general usage. No single sensor system provides a complete and accurate solution for the detection of smoking, the characterization of smoke exposure and other behavioral characteristics of smoking. This systematic review has addressed some successes of wearables in revealing interesting smoking-related phenomena. However, the review has identified a variety of challenges and obstacles to be addressed in future research. 
First, no wearable sensor system reached an accuracy of 100\% (even in controlled laboratory settings) in the detection of smoking-related features. Existing research targeted all major behavioral and physiological manifestations of cigarette smoking (e.g., lighting, hand gestures); however, body-worn or intraoral chemical sensors could be explored for the detection of smoking and the measurement of smoke exposure. Direct targeting of key chemicals, such as nicotine, may offer a universal approach for monitoring traditional and electronic cigarettes. To improve detection accuracy, further methodological improvements targeting signal processing and pattern recognition should be explored for the sensors currently in use.

Second, very few studies provide quantifiable evidence of user comfort, acceptability and adherence during the studies. These should be assessed in a standardized manner by developing a psychometrically validated questionnaire directed specifically to sensors for monitoring cigarette smoking. Future studies should pay special attention to the objective measurement of adherence, which is critical for the reliability of measurements. Additional sensors may need to be integrated into the wearable sensors, specifically with the purpose of identifying if the wearable is being used.

Third, most wearables have been tested in research settings, and only a few prototypes have been tested for accuracy or applicability under real-life conditions. The huge variability of unscripted human behavior and the impact of a myriad of contextual factors may present significant challenges to some of the sensor systems that test well in the laboratory. Future studies should focus on realistic evaluations under free-living conditions.

Fourth, many of the presented devices operate off-line. The development of real-time detection and notification capabilities may pave the way for the development of sensor-based smoking interventions.

\section{Conclusions}

This paper presents a systematic review of the state-of-the-art wearable technologies for an objective monitoring of smoking, a crucial process for timely interventions to curb smoking. Existing approaches were thoroughly examined in this review, and upcoming technologies were also identified. The review found that present-day research is now focusing upon improving accuracy, testing outside of restricted laboratory conditions, enhancing the comfort level of sensor systems, determining efficient classification methods, and improving signal processing procedures. If these existing challenges can be addressed, wearable sensors may substantially contribute to reducing the mortality rate due to cigarette smoking.

Author Contributions: The systematic search procedure was primarily set by three authors (M.H.I., S.W. and E.S.) and was executed with the assistance of the remaining authors (R.R.G. and S.T.). Two authors (M.H.I. and S.W.) independently screened the titles and abstracts of the publications retrieved through the database search; then one author (M.H.I.) carried out a full-text review of all relevant studies. M.H.I., S.W. and E.S. prepared the manuscripts; S.T. and R.R.G. contributed to proof-reading and finalizing the manuscript. All the authors read and approved the final manuscript.

Funding: This research was funded by the National Institute on Drug Abuse of the National Institutes of Health under Award Number R01DA035828.

Conflicts of Interest: Authors declare no financial conflict of interest. The content is solely the responsibility of the authors and does not necessarily represent official views of NIH.

\section{References}

1. WHO. International Classification of Diseases, 11th revision (ICD-11); WHO: Geneva, Switzerland, 2018. Available online: http://www.who.int/classifications/icd/en/ (accessed on 8 July 2018).

2. American Cancer Society. Harmful Chemicals in Tobacco Products. Available online: https://www.cancer. org/cancer/cancer-causes/tobacco-and-cancer/carcinogens-found-in-tobacco-products.html (accessed on 8 July 2018).

3. National Cancer Institute. Harms of Cigarette Smoking and Health Benefits of Quitting. Available online: https://www.cancer.gov/about-cancer/causes-prevention/risk/tobacco/cessation-fact-sheet (accessed on 8 July 2018). 
4. C. O. on S. and Health. Smoking and Tobacco Use; Surgeon General's Reports. 2004. Available online: http://www.cdc.gov/tobacco/data_statistics/sgr/2004/ (accessed on 8 July 2018).

5. What Happens to Your Body When You Smoke? Mercola.com. Available online: http://articles.mercola.com/ smoking-side-effects.aspx (accessed on 8 July 2018).

6. National Survey on Drug Use and Health. Available online: https://nsduhweb.rti.org/respweb/homepage.cfm (accessed on 8 July 2018).

7. C. O. on S. and Health. Smoking and Tobacco Use; Fact Sheet; Tobacco-Related Mortality. 9 May 2018. Available online: http://www.cdc.gov/tobacco/data_statistics/fact_sheets/health_effects/tobacco_related_ mortality/ (accessed on 8 July 2018).

8. C. O. on S. and Health. Smoking and Tobacco Use; Fact Sheet; Health Effects of Secondhand Smoke. 9 May 2018. Available online: http://www.cdc.gov/tobacco/data_statistics/fact_sheets/secondhand_smoke/health_effects/ (accessed on 8 July 2018).

9. C. O. on S. and Health. Smoking and Tobacco Use; Fact Sheet. 9 May 2018. Available online: http://www.cdc.gov/tobacco/data_statistics/fact_sheets/fast_facts/ (accessed on 8 July 2018).

10. Mathers, C.D.; Loncar, D. Projections of Global Mortality and Burden of Disease from 2002 to 2030. PLoS Med. 2006, 3, e442. [CrossRef] [PubMed]

11. Xu, X.; Bishop, E.E.; Kennedy, S.M.; Simpson, S.A.; Pechacek, T.F. Annual Healthcare Spending Attributable to Cigarette Smoking. Am. J. Prev. Med. 2015, 48, 326-333. [CrossRef] [PubMed]

12. Scholl, P.M.; Kücükyildiz, N.; Laerhoven, K.V. When do you light a fire: Capturing tobacco use with situated, wearable sensors. In Proceedings of the 2013 ACM Conference on Pervasive and Ubiquitous Computing Adjunct Publication, Zurich, Switzerland, 8-12 September 2013; pp. 1295-1304.

13. Current Cigarette Smoking Among Adults-United States, 2005-2014. Available online: https://www.cdc. gov/mmwr/preview/mmwrhtml/mm6444a2.htm (accessed on 8 July 2018).

14. G. Inc. Most U.S. Smokers Want to Quit, Have Tried Multiple Times. Gallup.com. Available online: https://news.gallup.com/poll/163763/smokers-quit-tried-multiple-times.aspx (accessed on 8 July 2018).

15. Gilpin, E.A.; Pierce, J.P.; Farkas, A.J. Duration of smoking abstinence and success in quitting. J. Natl. Cancer Inst. 1997, 89, 572-576. [CrossRef] [PubMed]

16. Khati, I.; Menvielle, G.; Chollet, A.; Younès, N.; Metadieu, B.; Melchior, M. What distinguishes successful from unsuccessful tobacco smoking cessation? Data from a study of young adults (TEMPO). Prev. Med. Rep. 2015, 2, 679-685. [CrossRef]

17. Irvin, J.E.; Hendricks, P.S.; Brandon, T.H. The increasing recalcitrance of smokers in clinical trials II: Pharmacotherapy trials. Nicotine Tob. Res. Off. J. Soc. Res. Nicotine Tob. 2003, 5, 27-35. [CrossRef]

18. Panel, D.G. Treating Tobacco Use and Dependence: 2008 Update; US Department of Health and Human Services: Atlanta, GA, USA, 2008.

19. Hartmann-Boyce, J.; Lancaster, T.; Stead, L.F. Print-based self-help interventions for smoking cessation. Cochrane Database Syst. Rev. 2014. [CrossRef]

20. Balanda, K.P.; Lowe, J.B.; O'Connor-Fleming, M.-L. Comparison of two self-help smoking cessation booklets. Tob. Control 1999, 8, 57-61. [CrossRef]

21. Text2Quit: Home. Available online: https://www.text2quit.com/text2quit/Display/display.aspx? CurrentXsltId=5 (accessed on 8 July 2018).

22. Michie, S.; Brown, J.; Geraghty, A.W.; Miller, S.; Yardley, L.; Gardner, B.; Shahab, L.; McEwen, A.; Stapleton, J.A.; West, R. Development of StopAdvisor: A theory-based interactive internet-based smoking cessation intervention. Transl. Behav. Med. 2012, 2, 263-275. [CrossRef]

23. Smoke Free-Quit Smoking Now. Available online: https://smokefreeapp.com/ (accessed on 8 July 2018).

24. Smokerlyzer. Available online: https://www.covita.net/smokerlyzer.html (accessed on 8 July 2018).

25. Hatziandreu, E.J.; Pierce, J.P.; Fiore, M.C.; Grise, V.; Novotny, T.E.; Davis, R.M. The reliability of self-reported cigarette consumption in the United States. Am. J. Public Health 1989, 79, 1020-1023. [CrossRef]

26. Hecht, S.S. Similar Uptake of Lung Carcinogens by Smokers of Regular, Light, and Ultralight Cigarettes. Cancer Epidemiol. Biomarkers Prev. 2005, 14, 693-698. [CrossRef]

27. Velicer, W.F.; Prochaska, J.O.; Rossi, J.S.; Snow, M.G. Assessing outcome in smoking cessation studies. Psychol. Bull. 1992, 111, 23-41. [CrossRef] [PubMed]

28. Shiffman, S.; Stone, A.A.; Hufford, M.R. Ecological momentary assessment. Annu. Rev. Clin. Psychol. 2008, 4, 1-32. [CrossRef] [PubMed] 
29. Klasnja, P.; Pratt, W. Healthcare in the pocket: Mapping the space of mobile-phone health interventions. J. Biomed. Inform. 2012, 45, 184-198. [CrossRef] [PubMed]

30. Hatsukami, D.K.; Hertsgaard, L.A.; Vogel, R.I.; Jensen, J.A.; Murphy, S.E.; Hecht, S.S.; Carmella, S.G.; Al'Absi, M.; Joseph, A.M.; Allen, S.S. Reduced Nicotine Content Cigarettes and Nicotine Patch. Cancer Epidemiol. Biomarkers Prev. 2013, 22, 1015-1024. [CrossRef]

31. Schlam, T.R.; Baker, T.B. Interventions for Tobacco Smoking. Annu. Rev. Clin. Psychol. 2013, 9, 675-702. [CrossRef]

32. Chamberlain, C.; O'Mara-Eves, A.; Porter, J.; Coleman, T.; Perlen, S.M.; Thomas, J.; McKenzie, J.E. Psychosocial interventions for supporting women to stop smoking in pregnancy. In Cochrane Database of Systematic Reviews; The Cochrane Collaboration, Ed.; John Wiley \& Sons, Ltd.: Chichester, UK, 2013.

33. Maciosek, M.V.; LaFrance, A.B.; Dehmer, S.P.; McGree, D.A.; Xu, Z.; Flottemesch, T.J.; Solberg, L.I. Health Benefits and Cost-Effectiveness of Brief Clinician Tobacco Counseling for Youth and Adults. Ann. Fam. Med. 2017, 15, 37-47. [CrossRef]

34. Schuck, K.; Otten, R.; Kleinjan, M.; Bricker, J.B.; Engels, R.C. Effectiveness of proactive telephone counselling for smoking cessation in parents: Study protocol of a randomized controlled trial. BMC Public Health 2011, 11, 732. [CrossRef]

35. Patrick, D.L.; Cheadle, A.; Thompson, D.C.; Diehr, P.; Koepsell, T.; Kinne, S. The validity of self-reported smoking: A review and meta-analysis. Am. J. Public Health 1994, 84, 1086-1093. [CrossRef]

36. Shiffman, S.; Gwaltney, C.J.; Balabanis, M.H.; Liu, K.S.; Paty, J.A.; Kassel, J.D.; Hickcox, M.; Gnys, M. Immediate antecedents of cigarette smoking: An analysis from ecological momentary assessment. J. Abnorm. Psychol. 2002, 111, 531-545. [CrossRef]

37. Shihadeh, A.; Antonios, C.; Azar, S. A portable, low-resistance puff topography instrument for pulsating, high-flow smoking devices. Behav. Res. Methods 2005, 37, 186-191. [CrossRef]

38. Benowitz, N.L.; Jacob, P.; Hatsukami, D.; Severson, H.; Hall, S.; Yu, L. Biochemical verification of tobacco use and cessation. Nicotine Tob. Res. 2002, 4, 149-159. [CrossRef] [PubMed]

39. Höfer, I.; Nil, R.; Bättig, K. Nicotine yield as determinant of smoke exposure indicators and puffing behavior. Pharmacol. Biochem. Behav. 1991, 40, 139-149. [CrossRef]

40. Gubbi, J.; Marusic, S.; Palaniswami, M. Smoke detection in video using wavelets and support vector machines. Fire Saf. J. 2009, 44, 1110-1115. [CrossRef]

41. Pavlovic, V.I.; Sharma, R.; Huang, T.S. Visual interpretation of hand gestures for human-computer interaction: A review. IEEE Trans. Pattern Anal. Mach. Intell. 1997, 19, 677-695. [CrossRef]

42. Stitt, J.P.; Kozlowski, L.T. A System for Automatic Quantification of Cigarette Smoking Behavior. In Proceedings of the 2006 International Conference of the IEEE Engineering in Medicine and Biology Society, Honolulu, HI, USA, 17-21 July 2006; pp. 4771-4774.

43. CReSS Pocket-Borgwaldt-Hauni GmbH. Available online: https://www.borgwaldt.com/en/products/smokingmachines/smoking-topography-devices/cress-pocket.html (accessed on 8 July 2018).

44. Brinkman, M.C.; Kim, H.; Chuang, J.C.; Kroeger, R.R.; Deojay, D.; Clark, P.I.; Gordon, S.M. Comparison of True and Smoothed Puff Profile Replication on Smoking Behavior and Mainstream Smoke Emissions. Chem. Res. Toxicol. 2015, 28, 182-190. [CrossRef] [PubMed]

45. Wu, P.; Hsieh, J.; Cheng, J.; Cheng, S.; Tseng, S. Human Smoking Event Detection Using Visual Interaction Clues. In Proceedings of the 2010 20th International Conference on Pattern Recognition, Istanbul, Turkey, 3-26 August 2010; pp. 4344-4347.

46. Mukhopadhyay, S.C. Wearable Sensors for Human Activity Monitoring: A Review. IEEE Sens. J. 2015, 15, 1321-1330. [CrossRef]

47. Li, I.; Dey, A.K.; Forlizzi, J. Understanding My Data, Myself: Supporting Self-reflection with Ubicomp Technologies. In Proceedings of the 13th International Conference on Ubiquitous Computing, New York, NY, USA, 8 November-1 December 2011; pp. 405-414.

48. Moher, D.; Liberati, A.; Tetzlaff, J.; Altman, D.G.; PRISMA Group. Preferred Reporting Items for Systematic Reviews and Meta-Analyses: The PRISMA Statement. PLoS Med. 2009, 6, e1000097. [CrossRef]

49. West, R. Tobacco smoking: Health impact, prevalence, correlates and interventions. Psychol. Health 2017, 32, 1018-1036. [CrossRef]

50. Shiffman, S.; Rathbun, S.L. Point process analyses of variations in smoking rate by setting, mood, gender, and dependence. Psychol. Addict. Behav. 2011, 25, 501-510. [CrossRef] 
51. Peretti-Watel, P.; Constance, J.; Guilbert, P.; Gautier, A.; Beck, F.; Moatti, J.-P. Smoking too few cigarettes to be at risk? Smokers' perceptions of risk and risk denial, a French survey. Tob. Control 2007, 16, 351-356. [CrossRef]

52. Griffiths, R.R.; Henningfield, J.E.; Bigelow, G.E. Human cigarette smoking: Manipulation of number of puffs per bout, interbout interval and nicotine dose. J. Pharmacol. Exp. Ther. 1982, 220, 256-265. [PubMed]

53. Sazonov, E.; Metcalfe, K.; Lopez-Meyer, P.; Tiffany, S. RF hand gesture sensor for monitoring of cigarette smoking. In Proceedings of the 2011 Fifth International Conference on Sensing Technology, Palmerston North, New Zealand, 28 November-1 December 2011; pp. 426-430.

54. Scholl, P.M.; van Laerhoven, K. A Feasibility Study of Wrist-Worn Accelerometer Based Detection of Smoking Habits. In Proceedings of the 2012 Sixth International Conference on Innovative Mobile and Internet Services in Ubiquitous Computing, Palermo, Italy, 4-6 July 2012; pp. 886-891.

55. How to Smoke a Cigarette. Wikihow. Available online: https://www.wikihow.com/Smoke-a-Cigarette (accessed on 8 July 2018).

56. Rodenstein, D.O.; Stănescu, D.C. Pattern of inhalation of tobacco smoke in pipe, cigarette, and never smokers. Am. Rev. Respir. Dis. 1985, 132, 628-632. [PubMed]

57. Echebarria, I.T.U.; Imtiaz, S.A.; Peng, M.; Rodriguez-Villegas, E. Monitoring smoking behaviour using a wearable acoustic sensor. In Proceedings of the 2017 39th Annual International Conference of the IEEE Engineering in Medicine and Biology Society (EMBC), Seogwipo, Korea, 11-15 July 2017; pp. 4459-4462.

58. Omvik, P. How smoking affects blood pressure. Blood Press. 1996, 5, 71-77. [CrossRef] [PubMed]

59. Ramakrishnan, S.; Bhatt, K.; Dubey, A.K.; Roy, A.; Singh, S.; Naik, N.; Seth, S.; Bhargava, B. Acute electrocardiographic changes during smoking: An observational study. BMJ Open. 2013, 3, e002486. [CrossRef] [PubMed]

60. Scholl, P.M.; van Laerhoven, K. Lessons learned from designing an instrumented lighter for assessing smoking status. In Proceedings of the 2017 ACM International Joint Conference on Pervasive and Ubiquitous Computing and Proceedings of the 2017 ACM International Symposium on Wearable Computers on-UbiComp '17, Maui, HI, USA, 11-15 September 2017; pp. 1016-1021.

61. Imtiaz, M.; Ramos-Garcia, R.; Senyurek, V.; Tiffany, S.; Sazonov, E. Development of a Multisensory Wearable System for Monitoring Cigarette Smoking Behavior in Free-Living Conditions. Electronics 2017, 6, 104. [CrossRef] [PubMed]

62. Quitbit|Smart Lighters to Help Track, Reduce \& Quit Smoking. Available online: http://www.quitbitlighter. com/ (accessed on 8 July 2018).

63. Lopez-Meyer, P. Detection of Hand-to-Mouth Gestures Using a RF Operated Proximity Sensor for Monitoring Cigarette Smoking. Open Biomed. Eng. J. 2013, 7, 41-49. [CrossRef] [PubMed]

64. Tang, Q.; Vidrine, D.; Crowder, E.; Intille, S. Automated Detection of Puffing and Smoking with Wrist Accelerometers. In Proceedings of the 8th International Conference on Pervasive Computing Technologies for Healthcare, Oldenburg, Germany, 20-23 May 2014.

65. Cole, C.A.; Thrasher, J.F.; Strayer, S.M.; Valafar, H. Resolving ambiguities in accelerometer data due to location of sensor on wrist in application to detection of smoking gesture. In Proceedings of the 2017 IEEE EMBS International Conference on Biomedical Health Informatics (BHI), Orlando, FL, USA, 16-19 February 2017; pp. 489-492.

66. Cole, C.A.; Anshari, D.; Lambert, V.; Thrasher, J.F.; Valafar, H. Detecting Smoking Events Using Accelerometer Data Collected Via Smartwatch Technology: Validation Study. JMIR mHealth uHealth 2017, 5, e189. [CrossRef]

67. Shoaib, M.; Scholten, H.; Havinga, P.J.M.; Incel, O.D. A hierarchical lazy smoking detection algorithm using smartwatch sensors. In Proceedings of the 2016 IEEE 18th International Conference on e-Health Networking, Applications and Services (Healthcom), Munich, Germany, 14-17 September 2016; pp. 1-6.

68. Añazco, E.V.; Lopez, P.R.; Lee, S.; Byun, K.; Kim, T.-S. Smoking Activity Recognition Using a Single Wrist IMU and Deep Learning Light. In Proceedings of the 2nd International Conference on Digital Signal Processing-ICDSP 2018, Tokyo, Japan, 25-27 February 2018; pp. 48-51.

69. SmokeBeat-Apps on Google Play. Available online: https://play.google.com/store/apps/details?id=com. somatix.smokebeat\&hl=en_US (accessed on 18 August 2019).

70. Skinner, A.L.; Stone, C.J.; Doughty, H.; Munafò, M.R. StopWatch: The Preliminary Evaluation of a Smartwatch-Based System for Passive Detection of Cigarette Smoking. Nicotine Tob. Res. 2018, 21, 257-261. [CrossRef] 
71. Bhandari, B.; Lu, J.; Zheng, X.; Rajasegarar, S.; Karmakar, C. Non-invasive sensor based automated smoking activity detection. In Proceedings of the 2017 39th Annual International Conference of the IEEE Engineering in Medicine and Biology Society (EMBC), Seogwipo, Korea, 11-15 July 2017; pp. 845-848.

72. Raiff, B.; Karataş, Ç.; McClure, E.; Pompili, D.; Walls, T. Laboratory Validation of Inertial Body Sensors to Detect Cigarette Smoking Arm Movements. Electronics 2014, 3, 87-110. [CrossRef]

73. Lu, J.; Wang, J.; Zheng, X.; Karmakar, C.; Rajasegarar, S. Detection of Smoking Events from Confounding Activities of Daily Living. In Proceedings of the Australasian Computer Science Week Multiconference on ACSW 2019, Sydney, Australia, 29-31 January 2019; pp. 1-9.

74. Parate, A.; Chiu, M.-C.; Chadowitz, C.; Ganesan, D.; Kalogerakis, E. RisQ: Recognizing smoking gestures with inertial sensors on a wristband. In Proceedings of the 12th annual international conference on Mobile systems, applications, and services-MobiSys '14, Bretton Woods, NH, USA, 16-19 June 2014; pp. 149-161.

75. Kim, A.; Golnaraghi, M.F. A quaternion-based orientation estimation algorithm using an inertial measurement unit. In Proceedings of the PLANS 2004. Position Location and Navigation Symposium (IEEE Cat. No. 04CH37556), Monterey, CA, USA, 26-29 April 2004; pp. 268-272.

76. Akyazi, O.; Batmaz, S.; Kosucu, B.; Arnrich, B. SmokeWatch: A smartwatch smoking cessation assistant. In Proceedings of the 2017 25th Signal Processing and Communications Applications Conference (SIU), Antalya, Turkey, 15-18 May 2017; pp. 1-4.

77. Parate, A.; Ganesan, D. Detecting Eating and Smoking Behaviors Using Smartwatches. In Mobile Health; Rehg, J.M., Murphy, S.A., Kumar, S., Eds.; Springer International Publishing: Cham, Germany, 2017; pp. 175-201.

78. Petrović, M.; Petrovic, J.; Simić, G.; Ilić, I.; Daničić, A.; Vukčević, M.; Bojović, B.; Hadžievski, L.; Allsop, T.; Webb, D.J. A new method for respiratory-volume monitoring based on long-period fibre gratings. In Proceedings of the 2013 35th Annual International Conference of the IEEE Engineering in Medicine and Biology Society (EMBC), Osaka, Japan, 3-7 July 2013; pp. 2660-2663.

79. Chen, G.; de la Cruz, I.; Rodriguez-Villegas, E. Automatic lung tidal volumes estimation from tracheal sounds. In Proceedings of the 2014 36th Annual International Conference of the IEEE Engineering in Medicine and Biology Society, Chicago, IL, USA, 26-30 August 2014; pp. 1497-1500.

80. Goto, E.; Noshiro, M.; Hosaka, H.; Minamitani, H. Ambulatory non-calibration measurement of tidal volume using optical fiber sensors. In Proceedings of the 17th International Conference of the Engineering in Medicine and Biology Society, Montreal, QC, Canada, 20-24 September 1995; pp. 1037-1038.

81. Retory, Y.; Niedzialkowski, P.; de Picciotto, C.; Bonay, M.; Petitjean, M. New Respiratory Inductive Plethysmography (RIP) Method for Evaluating Ventilatory Adaptation during Mild Physical Activities. PLoS ONE 2016, 11, e0151983. [CrossRef]

82. Zhang, Z.; Zheng, J.; Wu, H.; Wang, W.; Wang, B.; Liu, H. Development of a Respiratory Inductive Plethysmography Module Supporting Multiple Sensors for Wearable Systems. Sensors 2012, 12, 13167-13184. [CrossRef] [PubMed]

83. Cohn, M.A.; Rao, A.S.; Broudy, M.; Birch, S.; Watson, H.; Atkins, N.; Davis, B.; Stott, F.D.; Sackner, M.A. The respiratory inductive plethysmograph: A new non-invasive monitor of respiration. Bull. Eur. Physiopathol. Respir. 1982, 18, 643-658. [PubMed]

84. Fiamma, M.-N.; Samara, Z.; Baconnier, P.; Similowski, T.; Straus, C. Respiratory inductive plethysmography to assess respiratory variability and complexity in humans. Respir. Physiol. Neurobiol. 2007, 156, $234-239$. [CrossRef] [PubMed]

85. Rymut, R.; Slotty, E.; Kini, N. Method and Apparatus for Monitoring Respiration Using Signals from a Piezoelectric Sensor Mounted on a Substrate. U.S. Patent 6517497B2, 11 February 2003.

86. Tobin, M.J.; Jenouri, G.; Sackner, M.A. Subjective and objective measurement of cigarette smoke inhalation. Chest 1982, 82, 696-700. [CrossRef]

87. Taylor, D.R.; Reid, W.D.; Pare, P.D.; Fleetham, J.A. Cigarette smoke inhalation patterns and bronchial reactivity. Thorax 1988, 43, 65-70. [CrossRef]

88. Charles, F.K.; Krautter, G.R.; Mariner, D.C. Post-puff respiration measures on smokers of different tar yield cigarettes. Inhal. Toxicol. 2009, 21, 712-718. [CrossRef]

89. Duffty, P.; Spriet, L.; Bryan, M.H.; Bryan, A.C. Respiratory induction plethysmography (Respitrace): An evaluation of its use in the infant. Am. Rev. Respir. Dis. 1981, 123, 542-546. 
90. Sazonov, E.; Lopez-Meyer, P.; Tiffany, S. A wearable sensor system for monitoring cigarette smoking. J. Stud. Alcohol Drugs 2013, 74, 956-964. [CrossRef]

91. Ali, A.A.; Hossain, S.M.; Hovsepian, K.; Rahman, M.M.; Plarre, K.; Kumar, S. mPuff: Automated detection of cigarette smoking puffs from respiration measurements. In Proceedings of the 2012 ACM/IEEE 11th International Conference on Information Processing in Sensor Networks (IPSN), Beijing, China, 16-19 April 2012; pp. 269-280.

92. Nongpoh, B.; Ray, R.; Dutta, S.; Banerjee, A. AutoSense: A Framework for Automated Sensitivity Analysis of Program Data. IEEE Trans. Softw. Eng. 2017, 43, 1110-1124. [CrossRef]

93. Ramos-Garcia, R.I.; Imtiaz, M.H.; Sazonov, E.; Tiffany, S.T. Evaluation of RIP sensor calibration stability for daily estimation of lung volume. In Proceedings of the 2017 Eleventh International Conference on Sensing Technology (ICST), Sydney, Australia, 4-6 December 2017; pp. 1-5.

94. Wang, H.; Yen, C.; Liang, J.; Wang, Q.; Liu, G.; Song, R. A Robust Electrode Configuration for Bioimpedance Measurement of Respiration. J. Healthc. Eng. 2014, 5, 313-328. [CrossRef]

95. Lopez-Meyer, P.; Sazonov, E. Automatic breathing segmentation from wearable respiration sensors. In Proceedings of the 2011 Fifth International Conference on Sensing Technology, Palmerston North, New Zealand, 28 November-1 December 2011; pp. 156-160.

96. Ramos-Garcia, R.I.; Tiffany, S.; Sazonov, E. Using respiratory signals for the recognition of human activities. In Proceedings of the 2016 38th Annual International Conference of the IEEE Engineering in Medicine and Biology Society (EMBC), Orlando, FL, USA, 16-20 August 2016; pp. 173-176.

97. Senyurek, V.Y.; Imtiaz, M.H.; Belsare, P.; Tiffany, S.; Sazonov, E. A Comparison of SVM and CNN-LSTM Based Approach for Detecting Smoke Inhalations from Respiratory signal. In Proceedings of the 2019 41st Annual International Conference of the IEEE Engineering in Medicine and Biology Society (EMBC), Berlin, Germany, 23-27 July 2019; pp. 3262-3265.

98. Belsare, P.; Senyurek, V.Y.; Imtiaz, M.H.; Ti_any, S.; Sazonov, E. Computation of Cigarette Smoke Exposure Metrics from Breathing. IEEE Trans. Biomed. Eng.. submitted July 2019.

99. Cui, J.; Wang, L.; Gu, T.; Tao, X.; Lu, J. An Audio-based Hierarchical Smoking Behavior Detection System Based on A Smart Neckband Platform. In Proceedings of the 13th International Conference on Mobile and Ubiquitous Systems: Computing, Networking and Services, New York, NY, USA, 28 November-1 December 2016; pp. 190-199.

100. Imtiaz, M.H.; Hossain, D.; Senyurek, V.Y.; Belsare, P.; Ti_any, S.; Sazonov, E. Validation of a Wearable Egocentric Camera as a Monitoring Tool of Free-living Cigarette Smoking. J. Nicotine Tob. Res.. Accepted October 2019.

101. Imtiaz, M.H.; Hossain, D.; Senyurek, V.Y.; Ti_any, S.; Sazonov, E. Estimation of Behavioural Metrics of Cigarette Smoking from a Wearable Egocentric Camera. IEEE J. Biomed. Health Inform.. submitted August 2019.

102. Lopez-Meyer, P.; Tiffany, S.; Patil, Y.; Sazonov, E. Monitoring of Cigarette Smoking Using Wearable Sensors and Support Vector Machines. IEEE Trans. Biomed. Eng. 2013, 60, 1867-1872. [CrossRef] [PubMed]

103. Patil, Y.; Lopez-Meyer, P.; Tiffany, S.; Sazonov, E. Detection of cigarette smoke inhalations from respiratory signals using reduced feature set. In Proceedings of the 2013 35th Annual International Conference of the IEEE Engineering in Medicine and Biology Society (EMBC), Osaka, Japan, 3-7 July 2013; pp. 6031-6034.

104. Patil, Y.; Tiffany, S.; Sazonov, E. Understanding smoking behavior using wearable sensors: Relative importance of various sensor modalities. In Proceedings of the 2014 36th Annual International Conference of the IEEE Engineering in Medicine and Biology Society, Chicago, IL, USA, 26-30 August 2014; pp. 6899-6902.

105. Berry, D.; Bell, J.; Sazonov, E. Detection of cigarette smoke inhalations from respiratory signals using decision tree ensembles. SoutheastCon 2015, 2015, 1-4.

106. Lopez-Meyer, P.; Tiffany, S.; Sazonov, E. Identification of cigarette smoke inhalations from wearable sensor data using a Support Vector Machine classifier. In Proceedings of the 2012 Annual International Conference of the IEEE Engineering in Medicine and Biology Society, San Diego, CA, USA, 28 August-1 September 2012; pp. 4050-4053.

107. Saleheen, N.; Ali, A.A.; Hossain, S.M.; Sarker, H.; Chatterjee, S.; Marlin, B.; Ertin, E.; Al'Absi, M.; Kumar, S. puffMarker: A Multi-Sensor Approach for Pinpointing the Timing of First Lapse in Smoking Cessation. In Proceedings of the 2015 ACM International Joint Conference on Pervasive and Ubiquitous Computing, Osaka, Japan, 7-11 September 2015; pp. 999-1010. 
108. Senyurek, V.; Imtiaz, M.; Belsare, P.; Tiffany, S.; Sazonov, E. Cigarette Smoking Detection with an Inertial Sensor and A Smart Lighter. Sensors 2019, 19, 570. [CrossRef]

109. Senyurek, V.Y.; Imtiaz, M.H.; Belsare, P.; Tiffany, S.; Sazonov, E. Smoking detection based on regularity analysis of hand to mouth gestures. Biomed. Signal Process. Control 2019, 51, 106-112. [CrossRef]

110. Senyurek, V.Y.; Imtiaz, M.H.; Belsare, P.; Ti_any, S.; Sazonov, E. A CNN-LSTM Neural Network for Recognition Cigarette Smoking Inhalation in Smoking Events Using Wearable Sensors. Submitted to the Biomedical Engineering Letters. Springer.

111. Imtiaz, M.H.; Senyurek, V.Y.; Belsare, P.; Tiffany, S.; Sazonov, E. Objective Detection of Cigarette Smoking from Physiological Sensor Signals. In Proceedings of the 2019 41st Annual International Conference of the IEEE Engineering in Medicine and Biology Society (EMBC), Berlin, Germany, 23-27 July 2019; pp. 3563-3566.

112. Wattal, S.; Spear, S.K.; Imtiaz, M.H.; Sazonov, E. A polypyrrole-coated textile electrode and connector for wearable ECG monitoring. In Proceedings of the 2018 IEEE 15th International Conference on Wearable and Implantable Body Sensor Networks (BSN), Las Vegas, NV, USA, 4-7 March 2018; pp. 54-57.

113. Chen, T.; Zhang, X.; Jiang, H.; Asaeikheybari, G.; Goel, N.; Hooper, M.W.; Huang, M.C. Are you smoking? Automatic alert system helping people keep away from cigarettes. Smart Health 2018, 9-10, 158-169.

114. McClernon, F.J.; Choudhury, R.R. I Am Your Smartphone, and I Know You Are About to Smoke: The Application of Mobile Sensing and Computing Approaches to Smoking Research and Treatment. Nicotine Tob. Res. 2013, 15, 1651-1654. [CrossRef]

115. Qin, Y.; Qian, W.; Shojaati, N.; Osgood, N. Identifying Smoking from Smartphone Sensor Data and Multivariate Hidden Markov Models. In Social, Cultural, and Behavioral Modeling; Lee, D., Lin, Y.-R., Osgood, N., Thomson, R., Eds.; Springer International Publishing: Cham, Germany, 2017; Volume 10354, pp. 230-235.

(C) 2019 by the authors. Licensee MDPI, Basel, Switzerland. This article is an open access article distributed under the terms and conditions of the Creative Commons Attribution (CC BY) license (http://creativecommons.org/licenses/by/4.0/). 